Discussion Paper No. 15-013

\title{
The Effect of Electricity Taxation on the German Manufacturing Sector: A Regression Discontinuity Approach
}

Florens Flues and Benjamin Johannes Lutz

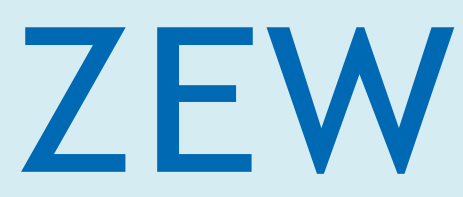

Zentrum für Europäische Wirtschaftsforschung $\mathrm{GmbH}$ Centre for European Economic Research 


\section{Discussion Paper No. 15-013 \\ The Effect of Electricity Taxation on the German Manufacturing Sector: A Regression Discontinuity Approach}

Florens Flues and Benjamin Johannes Lutz

Download this ZEW Discussion Paper from our ftp server:

http://ftp.zew.de/pub/zew-docs/dp/dp15013.pdf

Die Discussion Papers dienen einer möglichst schnellen Verbreitung von neueren Forschungsarbeiten des ZEW. Die Beiträge liegen in alleiniger Verantwortung der Autoren und stellen nicht notwendigerweise die Meinung des ZEW dar.

Discussion Papers are intended to make results of ZEW research promptly available to other economists in order to encourage discussion and suggestions for revisions. The authors are solely responsible for the contents which do not necessarily represent the opinion of the ZEW. 


\title{
The Effect of Electricity Taxation on the German Manufacturing Sector: A Regression Discontinuity Approach
}

\author{
Florens Flues* and Benjamin Johannes Lutz ${ }^{\dagger}$ \\ * Organisation for Economic Co-operation and Development, Paris, France \\ ${ }^{\dagger}$ Centre for European Economic Research, Mannheim, Germany
}

February 18, 2015

\begin{abstract}
Germany taxes electricity use since 1999. The government granted reduced rates to energy intensive firms in the industrial sector for addressing potentially adverse effects on firms' competitiveness. Firms that use more electricity than certain thresholds established by legislation, pay reduced marginal tax rates. As a consequence, the marginal tax rate is a deterministic and discontinuous function of electricity use. We identify and estimate the causal effects of these reduced marginal tax rates on the economic performance of firms using a regression discontinuity design. Our econometric analysis relies on official micro-data at the plant and firm level collected by the German Federal Statistical Office that cover the whole manufacturing sector. We do not find any systematic, statistically significant effects of the electricity tax on firms' turnover, exports, value added, investment and employment. The results suggest that eliminating the reduced marginal electricity tax rates could increase revenues for the government without adversely affecting firms' economic performance.

Keywords: Efficiency of Environmental Taxes, Control of Externalities, Regression Discontinuity Design

JEL-Classification: D22, H21, H23, Q41, Q48
\end{abstract}

\footnotetext{
* Organisation for Economic Co-operation and Development (OECD), 2 Rue Andre-Pascal, 75775 Paris CEDEX 16, France, Email: florens.flues@oecd.org.

${ }^{\dagger}$ Corresponding author. Centre for European Economic Research (ZEW), P.O. Box 1034 43, 68034 Mannheim, Germany, Email: lutz@zew.de.
} 


\section{Introduction}

Numerous countries recognize the challenges posed by resource scarcity, environmental pollution, and climate change. Responding to these challenges countries apply more and more market-based environmental policy instruments. While many economists consider market-based instruments theoretically superior than less flexible instruments, causal empirical evidence of their performance is still scarce.

Germany established an ad-quantum excise tax, a market based instrument, on electricity use in 1999. In this paper we evaluate the causal effects of this electricity tax on the economic performance of firms in the manufacturing sector. The government was concerned that the new electricity tax might harm the competitiveness of German firms. Therefore it provided relief to firms in the form of reduced marginal tax rates. The resulting variation in tax rates allows us to identify and estimate the causal effects of the reduced electricity tax on the economic performance of firms in the manufacturing sector. In particular, we investigate how firms' turnover, exports, value added, investment and employment responded to the tax.

We exploit a sharp regression discontinuity design to identify the causal effects of the German electricity tax. The marginal electricity tax rates are a deterministic and discontinuous function of firms' electricity use. Firms that use more electricity than certain thresholds established by legislation pay reduced marginal tax rates. These reduced marginal rates generate local random experiments at the thresholds from which they apply. We propose a sharp nonparametric regression discontinuity design (cf. Lee and Lemieux, 2010), which exploits the quasi-random variation in marginal electricity tax rates around the thresholds, to identify and estimate the causal effects of the differential tax rates.

While the theoretical concepts of market-based environmental regulation that underlie the German electricity tax exist for a long time, the implementation of instruments such as pollution taxes (Pigou, 1920) or tradable permit systems (Montgomery, 1972) have not gained momentum before the 1980s. The Clean Air Act Amendments of 1990 are seen as an important milestone for the application of such kind of regulation (Stavins, 1998). They spurred the development of allowance trading programs in the US during the 1990s with the aim to curb emissions of local pollutants such as sulphur dioxide $\left(\mathrm{SO}_{2}\right)$ and nitrogen oxides $\left(\mathrm{NO}_{x}\right)$. At the same time, several European countries including Sweden (1990), Denmark (1994), Norway, and Germany (both 1999) implemented environmental tax reforms to cut the emission of pollutants and to use the revenues for reducing the tax burden on labor 1

Despite the widespread regulatory intervention, the few studies that investigate the causal impact of market-based environmental regulation on economic performance of firms in the manufacturing sector, do not find significant adverse effects on economic performance of firms (see Arlinghaus, forthcoming and Martin, Muûls, and Wagner,

\footnotetext{
${ }^{1}$ For a survey of the environmental tax scheme implemented during the 1990s see Bosquet (2000)
} 
2013). Environmental performance, if addressed by the research, generally improves when compared to the pre-regulation outcome. Using a quasi-experimental research design with a generalized matching estimator, Fowlie, Holland, and Mansur (2012) examine the effectiveness of Southern California's $\mathrm{NO}_{x}$ trading program that has been introduced in the framework of the Clean Air Act Amendments of 1990. They show that the tradable permit system yielded emission reductions of 20 percent in comparison to the counterfactual, where facilities were regulated by command-and-control regulation. Martin, de Preux, and Wagner (2014) evaluate the impact of a carbon tax on the manufacturing industry in the UK using an instrumental variable approach. They provide robust evidence that the Climate Change Levy significantly decreased energy intensity and electricity use, while the economic performance of the firms remained unaffected. Petrick and Wagner (2014) investigate the effect of the EU Emissions Trading System on the German manufacturing industry with the help of semi-parametric matching estimators. They find that the scheme curbed the $\mathrm{CO}_{2}$ emissions by improving energy efficiency and fuel switching. According to their results the scheme had no impact on economic performance of the regulated firms.

Our study aims to contribute to this emerging literature by examining the causal effects of the German electricity tax on the firms of the manufacturing industry. In particular, we investigate the causal effect of the reduction in marginal tax rates for energy intensive firms. On the one hand, this strategy enables us to evaluate the effectiveness of the compensation scheme - on the other hand, it allows us to assess the effect of the tax itself, since the difference between marginal tax rates in some years is larger than the full tax rate in other years.

We make use of official microdata on the activities of the German manufacturing industry at the plant and firm level. The data is collected by the German Federal Statistical Office through a rigorous census of firms on production, costs and energy use. The participation in the surveys is mandatory by law for all plants with more than 20 employees and it includes information about the electricity use on firm and plant level. Given that the marginal tax rate is a deterministic function of the electricity use, we can calculate for each firm the electricity tax rate that applies.

The results suggest that the effects of the electricity tax on firms' turnover, exports, value added, investment and employment are neither systematic nor statistically significant. Eliminating the reduced marginal electricity tax rates may increase revenues for the government without adversely affecting the economic performance of firms. The additional tax revenues could be used to lower taxes that are widely regarded as particularly harmful to economic efficiency and growth such as taxes or social security contributions on labor, to consolidate budgets, or to finance new investments.

In the following, we first explain how the design of the German electricity tax leads to variation in firms' marginal electricity tax rate. Second, we discuss how we can identify and estimate the effects of the German electricity tax using a regression discontinuity design. Third, we describe the official data used in our analysis, which is collected by the 
German Statistical Office. Fourth, we present the results of our analysis and examine the robustness of our findings. We shortly discuss the implications of our results before we conclude.

\section{The German electricity tax and variation in the marginal tax rate}

The German electricity tax was introduced in 1999 aiming at improving energy efficiency and lowering labor costs. The new electricity tax increased the price on electricity incentivizing firms to reduce electricity use. The revenues lower social security contributions uniformly across firms, and thereby overall labor costs. We aim to assess how differences in marginal electricity tax rates affected firms' economic performance.

The electricity tax is levied on electricity use as an ad-quantum excise duty with a full rate of EUR 20.5 per MWh currently. This implies an effective tax on the carbon content in the average unit of electricity of EUR 44.4 per tonne of carbon dioxide $\left(\mathrm{CO}_{2}\right)$. Although this calculation assumes that the generation mix of electricity would not change, if the tax was levied on $\mathrm{CO}_{2}$ instead of on electricity, it indicates the significance of the electricity tax.

A comparison of the retail prices and the full rate shows that the tax significantly increases the retail price, between 27.1 percent in 2002 and 15.2 percent in 2005. Figure 1 shows the development of retail prices for electricity use and the full tax rate for the period from 1995 - 2005. The average price faced by a firm that consumes 2,000 MWh per annum ranged between EUR 65 and EUR 100 during this time period (Eurostat, 2014), which we take as the lower bound of the electricity price. As the upper bound of the electricity price we show the price for a household that consumes 3.5 MWh per annum, which ranged between EUR 115 and EUR 135 (Eurostat, 2014).

The government was concerned that the electricity tax may harm the competitiveness of German firms that are subject to competition from abroad. For that reason the government took at least two measures. First, it introduced the electricity tax in several steps until the full rate was reached in 2003 giving firms time to adjust to higher electricity prices. Second, it provided relief to manufacturing sectors through reduced tax rates.

The reduced tax rates apply from certain thresholds of electricity use onwards and are key to our identification strategy as subsequently outlined and described more formally in Section 3.1. While every user has to pay the same marginal tax rate for any use below the threshold, firms in the manufacturing sector are eligible for a reduced marginal tax rate for any use above the threshold. Table 1 shows that the tax is a piecewise linear function of electricity use $X$, that can be characterized as a set of two linear taxes, each relevant to only a particular range of $X$. Let $t(0)$ stand for the regular marginal tax rate and $t(1)$ for the reduced marginal tax rate. The known threshold, from which the reduced marginal tax rate applies, is denoted by $c$. Then, the tax function can be written 
Figure 1: Retail prices for electricity 1995 - 2005.

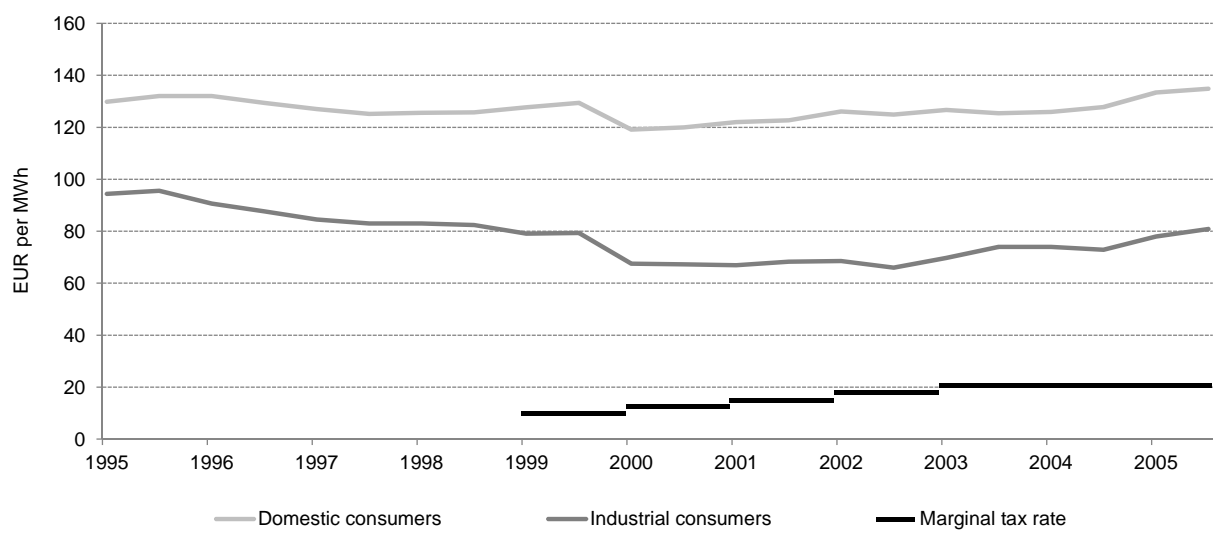

Notes: The price for domestic electricity use relates to a reference household that annually consumes $3.5 \mathrm{MWh}$ of which 1.3 MWh are consumed at night. The price for industrial electricity use relates to a reference firm that annually consumes 2,000 MWh (max. demand 0.5 MW; annual load 4,000 hours) Prices are denoted in EUR per MWh, include transmission, system services, meter rental, distribution and other services and exclude taxes and levies. Source: Eurostat (2014), own calculations.

as

$$
T(X)= \begin{cases}t(0) X & \text { if } X \leq c \\ t(1)(X-c)+t(0) c & \text { if } X>c .\end{cases}
$$

The thresholds of $50 \mathrm{MWh}$ or lower for a reduced marginal electricity tax rate may seem low; nevertheless many firms in the manufacturing sector consume about that much electricity. In 1999 when the electricity tax was introduced, about 25.2 percent of the firms in the data set used less than 100 MWh electricity per annum and about 13.1 percent of the firms used less than 50 MWh electricity per annum (see also Figure 2 in Section 4.3). Thus, many firms in the manufacturing sector consume about that much electricity, and are therefore directly affected by either having to pay the reduced or the full marginal electricity tax rate.

The reduced marginal tax rate for any electricity use above the threshold in a given year generates random variation in firms' marginal electricity tax rates. Whether firms face the full or reduced marginal tax rate is essentially chance due to arbitrarily set thresholds. We use this random assignment to identify the effects of the reduced marginal tax rates on firms' economic performance with a regression discontinuity design as explained in the following section.

Another type of electricity tax reduction is the so-called Spitzenausgleich. Remember that the revenues from the electricity tax are used to lower social security contributions on labor uniformly across firms. While firms benefit from reduced social security contributions they may end up with overall higher costs due the new electricity tax. The Spitzenausgleich reimburses a certain percentage of the potential additional burden from the new electricity tax net of the savings on social security contributions. The reimbursement rule and also the reduction in social security contributions have changed several times. 
Table 1: Marginal electricity tax rate.

\begin{tabular}{|c|c|c|c|c|c|c|c|}
\hline \multirow[b]{2}{*}{ Electricity use threshold } & \multicolumn{7}{|c|}{ Marginal electricity tax rate in EUR per MWh } \\
\hline & Until 1999 & 1999 & 2000 & 2001 & 2002 & 2003 & Until 2010 \\
\hline below $25 \mathrm{MWh}$ & 0 & 10 & 12.5 & 15 & 17.9 & 20.5 & 20.5 \\
\hline above $25 \mathrm{MWh}$ & 0 & 10 & 12.5 & 15 & 17.9 & 12.3 & 12.3 \\
\hline above $28.6 \mathrm{MWh}$ & 0 & 10 & 12.5 & 15 & 3.6 & 12.3 & 12.3 \\
\hline above $33 \mathrm{MWh}$ & 0 & 10 & 12.5 & 3 & 3.6 & 12.3 & 12.3 \\
\hline above $40 \mathrm{MWh}$ & 0 & 10 & 2.5 & 3 & 3.6 & 12.3 & 12.3 \\
\hline above $50 \mathrm{MWh}$ & 0 & 2 & 2.5 & 3 & 3.6 & 12.3 & 12.3 \\
\hline
\end{tabular}

The Spitzenausgleich applies only for electricity use above the same thresholds from which the reduced marginal electricity tax rate is granted. Thereby it may add to the potential effects of the reduced marginal tax rates. We expect that the effects of the reduced tax rate dominate around the thresholds given non-negligible administrative procedures for receiving the Spitzenausgleich. In the following we will therefore refer to the effects of the reduced tax rate, bearing in mind that some of effects may have been reinforced by the Spitzenausgleich.

In August 2006 exemptions to the electricity tax were granted for firms in the manufacturing sectors for the electricity consumed in various production processes. In particular, electricity used for electrolysis, production of glass, ceramics, fertilizers, metal production and processing, as well as chemical reduction processes was exempted from the electricity tax. The tax exemptions apply for all electricity consumed and thus not only from above certain threshold onwards. We do not have any information on how much electricity is used for these processes. From 2006 onwards a clean identification of firms that benefit from the reduced marginal electricity tax rate is not possible any more. We therefore analyze the effects of the reduced marginal electricity tax rate only until 2005.

As mentioned, the revenues from the electricity tax are used to lower social security contributions. Given that the reduction of social security contributions applies to all firms uniformly, we cannot measure the effect of the reduction in social security contributions. Neither can we assess the overall effect of the reform package, i.e., the introduction of a new electricity tax combined with the use of its revenues to lower social security contributions. What we aim to assess is how different marginal electricity tax rates affected firms' economic performance.

\section{Research design}

\subsection{Empirical approach}

Our goal is to identify the causal effect of the electricity tax on the economic performance of firms in the manufacturing sector. As ad-quantum excise duty, the electricity tax increases the price per unit of consumed electricity by the marginal tax rate $t$. We 
build our identification strategy on variations in the marginal tax rate. Firms that are energy intensive in terms of individual electricity use face a lower marginal tax rate in comparison to less energy intensive firms. In particular, the reduced tax rate applies, if the electricity use $X_{i}$ of firm $i$ exceeds the known threshold $c$ that is set by the regulatory authorities:

$$
t_{i}= \begin{cases}t_{i}(0) & \text { if } X_{i} \leq c \\ t_{i}(1) & \text { if } X_{i}>c\end{cases}
$$

where $t_{i}(0)$ denotes the regular marginal tax rate and $t_{i}(1)$ the reduced marginal tax rate, respectively. Hence, the tax reduction scheme creates a sharp discontinuity in the marginal tax rate as a function of the individual electricity use. This feature of the electricity tax allows us to identify and estimate the effect of the electricity tax for any given year by employing a sharp regression discontinuity design.

The profit maximizing firm equalizes marginal costs and marginal revenues by choosing the level of output and the combination of inputs subject to technological constraints. The discontinuity in the marginal tax rate and the resulting scheme of two different marginal tax rates creates variation across firms regarding the marginal costs associated with the use of electricity. We expect the firms to react to the regular and reduced marginal tax rate differently by adjusting the level of output and combination of inputs according to the marginal tax rate they face.

More specifically, we hypothesize that firms that face higher marginal taxes will have lower output relative to firms with low marginal costs. Two observations lead to this hypothesis. First, firms that have to pay the full tax rate face higher marginal costs for electricity use, and thus overall higher marginal costs, than firms that only need to pay the reduced tax rate. For minimizing costs, a firm equates the ratio of marginal costs of inputs to the ratio of the marginal products of output factors. A higher marginal cost for electricity use translates into higher overall costs for producing the same level of output. Thereby overall marginal costs are also higher for firms with higher marginal costs for electricity use. Second, if there are two types of firms in the market, those with low marginal costs are expected to produce a higher output than those with high marginal costs all else equal.

The economic outcomes we can observe with our dataset are firms' turnover, exports, value added, investment and employment. We expect that the turnover and exports of firms with the reduced tax rate will be higher than for those that face the full marginal tax rate. The intuition is that lower marginal costs allow the former firms to produce more. For the same reason we also expect that the value added, which is revenue minus costs, of firms with the reduced tax rate is higher than for firms with the full marginal tax rate.

The total effects of the reduced marginal tax rate on investment and employment can have either sign. With regard to investment, there is a direct effect, namely that higher production causes more investment. Yet, there is also an indirect effect in the opposite direction. Firms that face high marginal costs due to paying the full tax rate have an 
incentive to invest in new, more energy efficient production technology to mitigate their cost disadvantage. Thus the total effects may have either sign. Regarding employment there is, first, a direct effect from lower marginal costs to higher production and thus more employment. Second, there are indirect effects in addition, if firms with high marginal costs invest in new, more energy efficient technology. This new technology could either be less or more labor intensive than the old one. If it less labor intensive, the indirect effect goes in the same direction as the direct effect and we thus expect firms with the reduced tax rate to employ more labor. If the technology is, however, more labor intensive than the old one, the indirect effect goes in the opposite direction, i.e. firms that pay the full tax rate employ more labor. In total, we cannot hypothesize unambiguously what the effect of reduced tax rate on labor is.

Our identification strategy can be formalized using the potential outcomes framework introduced by the seminal work of Rubin $(1974,1977)$. The firms of the German manufacturing industry are assigned to two different groups. The binary variable $D_{i} \in\{0,1\}$ describes the treatment status of firm $i$. Let $D_{i}=1$ if the firm's electricity use $X_{i}$ exceeds the threshold $c$. Then the firm is subject to the reduced marginal tax rate $t_{i}(1)$ and is considered as treated. Let $D_{i}=0$ if the firm's electricity use $X_{i}$ is lower than the threshold $c$. In this case the full marginal tax rate $t_{i}(0)$ applies and the firm is assigned to the control group. Consequently, we denote the potential outcomes by

$$
Y_{i}= \begin{cases}Y_{i}(0) & \text { if } X_{i} \leq c \\ Y_{i}(1) & \text { if } X_{i}>c\end{cases}
$$

As shown in Equation 1, the assignment to the treatment group is a deterministic function of the electricity use $X_{i}$. Since we observe the electricity use $X_{i}$, we are able to identify if firm $i$ belongs to the treatment or the control group. Following the sharp regression discontinuity design framework outlined by Imbens and Lemieux (2008) and Lee and Lemieux (2010) we analyze the sharp discontinuity in the conditional expectation of the outcome given electricity use $X_{i}$ to unveil an average causal effect of the treatment:

$$
\tau=\lim _{x \downarrow c} E\left[Y_{i} \mid X_{i}=x\right]-\lim _{x \uparrow c} E\left[Y_{i} \mid X_{i}=x\right] .
$$

In the literature this term is interpreted as the local average treatment effect at the threshold (Imbens and Lemieux, 2008):

$$
\tau=E\left[Y_{i}(1)-Y_{i}(0) \mid X_{i}=c\right]
$$

Making use of assumptions we describe in Section 3.2, the treatment variation close to the threshold $c$ is considered as good as random. The random assignment implies that the discontinuity at the threshold $c$ identifies the treatment effect of interest. Consequently, we are able to identify the effect of the electricity tax reduction by comparing firms of the treatment and control group that are in the neighborhood of the threshold.

The level of a firm's electricity use is determined to a high degree by its size and the deployed production technology. Both characteristics develop over time and are 
based on a series of decisions. Therefore, the level of electricity use cannot be easily manipulated in the short run. The arbitrarily chosen thresholds lead to a situation where established firms that use similar quantities of electricity face different marginal tax rates ${ }^{2}$ Residual variation in the firm's individual electricity use might remain that is driven by exogenous factors. This residual materializes in the course of a year and its random character diminishes steadily. Due to the simplicity of the tax scheme, we assume that firms are able to make accurate production decisions based on the correct marginal costs associated with electricity use by frequently updating the underlying information.

The tax reduction scheme is implemented through reimbursement, i.e. firms whose electricity use exceeds the threshold may request reimbursement from the local tax and custom agency. We do not observe if firms that were assigned to the treatment group received the treatment. While the reimbursement procedure creates imperfect compliance, inference is still possible. We account for this case of encouraged treatment by performing an intent to treat analysis. We compare control and treatment group without regards to whether the tax reduction was actually claimed. Accordingly, the local average treatment effect measures in our case how the treatment assignment affected the firm's activities, as opposed to the desired measure of how the treatment itself affected the firm's activities (Pearl, 2000). For simplicity we will stick with the term local average treatment effect. Yet, one should bear in mind that the estimated treatment effect measures the intend to treat, i.e. the effect of the eligibility for the electricity tax reduction.

\subsection{Identifying assumptions}

The regression discontinuity design allows to identify local treatment effects under comparatively lax assumptions. Following Hahn, Todd and van der Klaauw (2001) and Lee and Lemieux (2010) we unfold the assumptions that underlie the approach and discuss them in light of the German electricity tax.

Assignment to the treatment group

First, the treatment assignment must be a monotone deterministic function of the assignment variable. This holds in our case, as firms that consume more electricity $X_{i}$ than the known threshold $c$ benefit from the tax reduction and are considered as treated, while firms that consume less face the full marginal tax rate (see Equation 2) and are considered as untreated. Second, the probability of treatment has to be a discontinuous function of the assignment variable. The probability to be treated, i.e. to benefit from the tax reduction, changes discontinuously at the threshold $c$, particularly $P\left[D_{i}=1 \mid X_{i}=x\right]$ is 0 for $x \leq c$ and 1 for $x>c$.

Inability to precisely control the assignment variable

The central assumption that underlies our identification strategy is that firms can-

\footnotetext{
${ }^{2}$ In Appendix D Table 11, we show that the results of our analysis are robust with respect to potential adjustment processes that might lead to lagged effects of the tax reduction.
} 
not precisely manipulate their individual electricity use. Lee (2008) shows that the treatment in the regression discontinuity design is random, if the assignment variable has a continuously distributed stochastic component, i.e. firms cannot precisely control their electricity use. We argue that this assumption is plausible in our setting for two reasons: First, complex production processes in the manufacturing industry make precise manipulation of a firm's electricity use difficult. Second, exogenous factors that drive electricity use lead to stochastic variation in electricity use. For example, market conditions impact a firm's production decisions and thereby its energy use. We will test this assumption in Section 5.1 by examining the empirical distribution of the assignment variable. No evidence for precisely controlling the assignment variable is found.

\section{Local continuity restriction}

In absence of treatment, the outcome variable has to evolve continuously with the assigment variable in the neighborhood of the threshold. If other factors create discontinuities in this relationship, a clear identification of the local treatment effect is not possible. In Section 5.1 we empirically investigate the evolution of each outcome variable as a function of the assignment variable electricity use for the years before the implementation of the electricity tax. In this way, we aim to detect other sources that create discontinuities in the relationships under investigation and thus might affect identification. No evidence for any prior discontinuities is found.

\section{Stable unit treatment value assumption}

The stable unit treatment value assumption (SUTVA) assumes, that the treatment status of a firm does not affect the outcomes for other firms. Hence, SUTVA excludes spill overs and general equilibrium effects across firms. This assumption cannot be directly tested. However, in Section 6 we will discuss the robustness of our results with regard to a potential violation of this assumption.

\subsection{Estimation}

The estimation of the local average treatment effect $\tau$ requires an estimator that shows good small sample properties and is suitable for inference at the boundary of the support of the regression function (here threshold $c$ ). Addressing these obstacles, Hahn, Todd, and van der Klaauw (2001) and Porter (2003) propose a non-parametric approach based on weighted local linear or polynomial regressions at both sides of the threshold. This estimator has become the standard choice for the estimation of local average treatment effects in the regression discontinuity literature. Yet, the estimator requires the selection of a bandwidth that determines the range around the threshold that is exploited for the estimation of the local regressions. We use a fully data-driven bandwidth algorithm developed by Imbens and Kalyanaraman (2012) in order to select the asymptotically optimal bandwidth.

We formalize the estimator of the local average treatment effect $\hat{\tau}$ at the threshold $c$ as described in Imbens and Kalyanaraman (2012):

$$
\hat{\tau}=\hat{\alpha}_{+}-\hat{\alpha}_{-}
$$


where $\hat{\alpha}_{+}$and $\hat{\alpha}_{-}$denote the constants of a weighted local linear regression. The weights are computed by applying a kernel function $K(\cdot)$ on the distance of each observation's score to the threshold $c$. The parameters are obtained by estimating two equations within two narrow windows left and right of the threshold that yield in the estimator $\hat{\alpha}_{+}$for only treated and the estimator $\hat{\alpha}_{-}$for only control firms:

$$
\begin{aligned}
& \left(\hat{\alpha}_{+}, \hat{\beta}_{+}\right)=\underset{\alpha, \beta}{\operatorname{argmin}} \sum_{i=1}^{N} \mathbf{1}_{X_{i}>c}\left(Y_{i}-\alpha-\beta\left(X_{i}-c\right)\right) K\left(\frac{X_{i}-c}{h}\right), \\
& \left(\hat{\alpha}_{-}, \hat{\beta}_{-}\right)=\underset{\alpha, \beta}{\operatorname{argmin}} \sum_{i=1}^{N} \mathbf{1}_{X_{i}<c}\left(Y_{i}-\alpha-\beta\left(X_{i}-c\right)\right) K\left(\frac{X_{i}-c}{h}\right),
\end{aligned}
$$

where $\mathbf{1}_{u}$ is an indicator function taking the value 1 if condition $u$ is fulfilled. In order to select the optimal bandwidth $h$ for the two windows, we employ the algorithm developed by Imbens and Kalyanaraman (2012). The default form of the kernel function $K(\cdot)$ in our set up is triangular. The computed standard errors are robust with respect to heteroskedasticity and show good finite sample properties $3^{3}$ Unless otherwise stated, the results that are presented in the remainder of this paper are estimated based on the procedure shown in Imbens and Kalyanaraman (2012).

\section{Data}

\subsection{Official Firm Data for Germany}

Our empirical analysis exploits official census micro-data of firms collected by the German Federal Statistical Office and the Statistical Offices of the German Federal States. The data are confidential but the German statistical offices provide remote data access to researchers for scientific purposes. Participation in surveys conducted by the German statistical offices is mandatory by law and many official German government statistics build on this data.

The dataset, called Amtliche Firmendaten für Deutschland - AFiD (Official Firm Data for Germany), records activities of the industrial sector on plant and firm level. It consists of several modules, which can be combined. In particular, we use two modules that capture activities of the German manufacturing industry.

The core of our dataset is the module AFiD-Panel Industrial Units. This longitudinal census combines annual results from the Monthly Report on Plant Operation, the Census on Production, and the Census on Investment. The AFiD-Panel Industrial Units is a census of all establishments - physical buildings or structures, i.e., plants. It provides detailed information on turnover, exports, employment, investment and firm affiliation.

This database is extended by the AFiD-Module Use of Energy. The AFiD-Module Use of Energy is a longitudinal census that comprises results from the Monthly Report

\footnotetext{
${ }^{3}$ The estimator of the local average treatment effect shown here is implemented using the STATA package developed by Calonico et al. (2014a). For the computation of the standard errors, we choose the convential fixed-matches variance estimator proposed in Calonico, Cattaneo, and Rocio (2014a, 2014b).
} 
on Plant Operation and the Census on Energy Use. It contains information about sale, purchase, generation, use, and distribution of electricity and fuels. Both the AFiDPanel Industrial Units and the AFiD-Module Use of Energy have the same group of respondents. These are all German plants that operate in the manufacturing industry and belong to firms that employ more than 20 persons.

Merging the AFiD-Panel Industrial Units with the module AFiD-Module Use of Energy we construct a data set comprising longitudinal census data on firm level covering a time span from 1995 to 2005 . This data cover pre-reform, reform and post-reform periods. Where necessary, we aggregate plant level data to the firm level using the firm affiliation provided within the AFiD-Panel Industrial Units.

\subsection{Cost Structure Survey}

We link the AFiD-Panel Industrial Units and the AFiD-Module Use of Energy with data from the Cost Structure Survey (CSS) to obtain information on the value added at the firm level 4

The CSS also conducted by the German Federal Statistical Office and the Statistical Offices of the German Federal States gives detailed information on the costs from capital, labor as well as value added of firms on an annual basis from 1995 - 2010.

In contrast to the AFiD-Panel Industrial Units and the AFiD-Module Use of Energy, the CSS collects data directly on firm level. It includes all firms with more than 500 employees. For firms with at least 20 and less than 500 employees, the statistical offices collect a random sample that is stratified by the number of employees and industry affiliation. These firms remain four years in the panel and are replaced by a new random sample afterwards. For the CSS, the same participation rules apply as for AFiD. The provision of the requested information is mandatory by law.

\subsection{Descriptive statistics}

In our analysis, we focus on German firms that belong to the sectors mining and quarrying (ISIC 1010-1429) and manufacturing (ISIC 1511-3720) 5 The data set comprises the assignment variable electricity use that determines if firms belong to treatment or control group, and five outcome variables. The outcome variables of our analysis are turnover, exports, investment, employment as measured by number of employees and value added. Turnover, exports, investment, and value added are denoted in 1,000 EUR. In addition we show electricity intensity as descriptive statistic that is computed by dividing the amount of electricity use by turnover. The resulting index is denoted in KWh per

\footnotetext{
${ }^{4}$ In particular we use the variable gross value added - for practical purposes referred to as value added throughout the paper.

${ }^{5}$ Regarding the classification by economic activity, we refer to the International Standard Industrial Classification of all economic activities (ISIC) Rev. 3.1, as adopted by the Statistical Commission of the United Nations.
} 
Table 2: Descriptive statistics.

\begin{tabular}{lcccccc}
\hline \hline & Mean & St. dev. & P10 & P 50 & P90 & N \\
\hline Panel A: 1995 & & & & & & \\
Electricity use (in MWh) & $1,346.66$ & $3,474.06$ & 37.40 & 284.92 & $3,170.90$ & 38,470 \\
Turnover (in 1000 EUR) & $13,155.15$ & $23,575.62$ & $1,423.09$ & $5,134.15$ & $31,759.60$ & 38,579 \\
Exports (in 1000 EUR) & $2,622.11$ & $7,802.80$ & 0 & 93.01 & $6,559.38$ & 38,579 \\
Investment (in 1000 EUR) & 594.14 & $1,378.32$ & 0 & 136.67 & $1,490.43$ & 32,975 \\
Employment & 104.56 & 154.27 & 22.50 & 51.00 & 235.67 & 38,579 \\
Electricity intensity (in EUR per KWh) & 0.1003 & 0.1247 & 0.0110 & 0.0577 & 0.2414 & 38,470 \\
Value added (in 1000 EUR) & - & - & - & - & - & - \\
Panel B: 2000 & & & & & & \\
Electricity use (in MWh) & $1,509.58$ & $3,968.69$ & 41.47 & 304.95 & $3,541.74$ & 38,784 \\
Turnover (in 1000 EUR) & $14,855.25$ & $27,579.86$ & $1,520.13$ & $5,462.99$ & $36,230.26$ & 38,873 \\
Exports (in 1000 EUR) & $3,726.30$ & $11,062.76$ & 0 & 129.68 & $9,378.87$ & 38,873 \\
Investment (in 1000 EUR) & 603.73 & $1,423.36$ & 0 & 135.71 & $1,518.55$ & 36,493 \\
Employment & 99.81 & 141.20 & 22.75 & 49.5 & 228 & 38,873 \\
Electricity intensity (in EUR per KWh) & 0.1020 & 0.1262 & 0.0108 & 0.0599 & 0.2397 & 38,784 \\
Value added (in 1000 EUR) & $8,945.63$ & $13,821.24$ & $1,036.60$ & $3,778.24$ & $22,868.13$ & 15,152 \\
Panel C: 2005 & & & & & & \\
Electricity use (in MWh) & $1,888.30$ & $4,938.04$ & 60.51 & 400.43 & $4,437.14$ & 36,158 \\
Turnover (in 1000 EUR) & $16,183.06$ & $30,413.63$ & $1,483.17$ & $5,740.41$ & $39,668.39$ & 37,329 \\
Exports (in 1000 EUR) & $4,950.96$ & $13,909.35$ & 0 & 302.92 & $12,822.16$ & 37,329 \\
Investment (in 1000 EUR) & 477.57 & $1,192.87$ & 0 & 90.62 & $1,192.46$ & 35,111 \\
Employment & 97.78 & 137.62 & 22.75 & 49.50 & 217.67 & 37,329 \\
Electricity intensity (in EUR per KWh) & 0.1201 & 0.1431 & 0.0144 & 0.0732 & 0.2773 & 35,897 \\
Value added (in 1000 EUR) & $9,502.641$ & $14,542.27$ & $1,039.019$ & $4,089.146$ & $24,673.86$ & 13,997 \\
\hline \hline
\end{tabular}

Notes: Turnover, investment and exports are denoted in EUR 1000. Electricity use relates to the taxable electricity use in MWh (not including self-generated electricity). Electricity intensity is denoted by electricity use devided by turnover. Source: Research Data Centres of the Statistical Offices Germany (2014): Official Firm Data for Germany (AFiD) - AFiD-Panel Industrial Units, AFiD-Module Use of Energy, and Cost Structure Survey, own calculations.

\section{EUR 6}

In Table 2 we present descriptive statistics for the original sample for the years 1995, 2000, and 2005:7 Our data set includes close to 40,000 observations per year. As explained in Section 4.1. AFiD is a modular data set based on several different mandatory censuses and surveys. Hence, the sample size varies depending on the variable under investigation and the associated census or survey 8 We have information on turnover,

\footnotetext{
${ }^{6}$ Electricity intensity may also be of interest as an outcome variable. Given its construction as electricity use over turnover and with electricity use being the assignment variable, it does, however, not provide any additional information to simply analysing turnover. Figure 9 and Figure 10 in Appendix A show the electricity intensity as function of electricity use for given years in order to shed some light on the previously described relationship.

${ }^{7}$ For all considered variables, outliers have been removed outside the $1^{\text {st }}$ and $99^{\text {th }}$ percentile.

${ }^{8}$ The characteristics turnover, exports, and employment are gathered monthly by the same census, the Monthly Report on Plant Operation. Investment and electricity use stem from different censuses, namely the Census on Investment, the Monthly Report on Plant Operation, and the Census on Energy Use. The Census on Investment is conducted yearly. While information on energy use was collected by the Monthly Report on a monthly basis from 1995 - 2002, an independent census on energy use was
} 
Figure 2: Histograms of electricity use in 1995, 2000, and 2005.
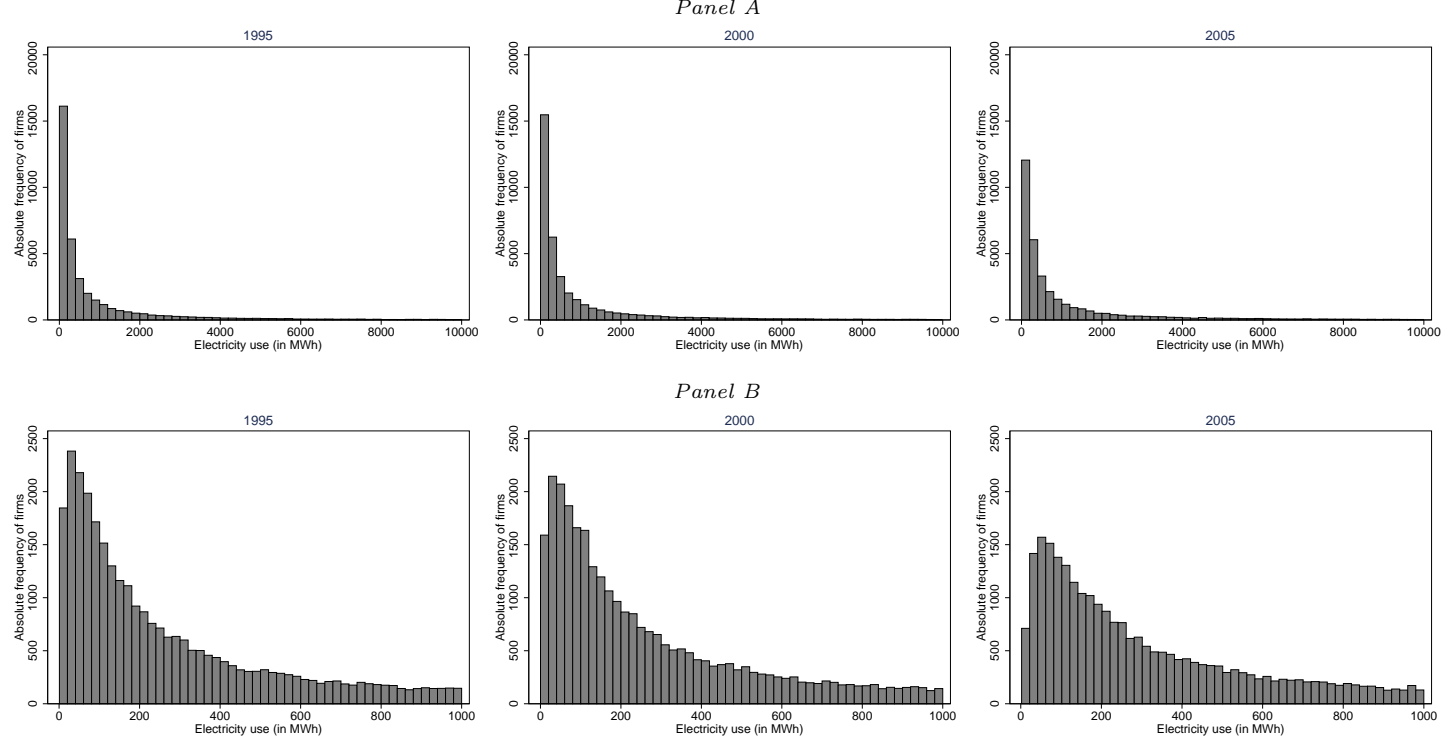

Notes: Source: Research Data Centres of the Statistical Offices Germany (2014): Official Firm Data for Germany (AFiD) - AFiD-Panel Industrial Units and AFiD-Module Use of Energy, own calculations.

exports, investment, employment, and electricity use for all firms of the manufacturing sector with more than 20 employees summing up to about 40,000 observations on an annual basis from 1995 - 2010. For value added, we have only information from a random sample of about 15,000 firms on an annual basis from 1999 - 2010.

Comparing 10th and 90th percentile of the outcome variables and electricity use (Table 2), firms are highly dispersed. The percentiles as well as a comparison of mean and median show that the distributions of firms over the considered variables are positively skewed. This reflects the high fraction of small and medium sized firms and their importance for the German economy. About 90 percent of these firms operate only a single plant.

Many firms operate around the thresholds for the reduced electricity rate, i.e., 50 MWh from 1999 to 25 MWh from 2003 onwards. Figure 2 shows histograms of the distribution of firms in the manufacturing sector ordered across their electricity use for the years 1995, 2000, and 2005. Each bin shows the absolute frequency of firms within the considered range. A bin corresponds to a $200 \mathrm{MWh}$ range in Panel A and a 20 MWh range in Panel B. Panel A shows very few firms with electricity use above 2,000 MWh while many more firms consume less than 2,000 MWh. The lowest bin in terms of electricity use, which corresponds to an electricity use of 0 to $200 \mathrm{MWh}$, contains close to 39.9 percent of all firms included in the data set in 2000. Panel B shows histograms that zoom into the range of firms consuming less than 1,000 MWh of electricity. These histograms show many more firms in the bins close to thresholds for a reduced electricity established in 2003. The corresponding Census on Energy Use collects information on energy use on a yearly basis from 2003 - 2010. Information about value added is collected by the annual Cost Structure Survey on a yearly basis from 1999 - 2010. 
tax rate, i.e., around $50 \mathrm{MWh}$ to $25 \mathrm{MWh}$, than in bins with higher electricity use.

\section{Empirical evidence}

\subsection{Testing for identifying assumptions}

In this section, we investigate the validity of our identification strategy. Applying the guideline set out by Lee and Lemieux (2010), we aim to confirm the assumptions that underlie the regression discontinuity design.

First, we examine the assumption that firms are unable to precisely control the assignment variable, i.e., electricity use. If this assumption holds, assignment to the treatment group is as good as locally random. According to Lee and Lemieux (2010) the incentive for sorting around the threshold is unproblematic, as long as the assignment variable contains a stochastic error component. In this case optimizing firms do not have precise control over the assignment variable resulting into local random assignment to the treatment.

The assumption of imprecise control of the assignment variable cannot be directly tested. Nevertheless, by examining first the aggregate empirical distribution of the assignment variable and then applying a more formal test on the continuity of the distribution developed by McCrary (2008), we are able to shed light on the validity of this assumption.

In Figure 3 we present histograms that illustrate the distribution of the assignment variable electricity use for the pre-treatment year 1995 and the treatment years 1999 - 2005. The support of the distribution is trimmed to a range of $100 \mathrm{MWh}$. The graphs show the absolute frequencies of firms computed over non-overlapping bins with a bandwidth of 1 MWh. Following Lee and Lemieux (2010) we choose binwidths as small as possible, that still allow us to see the shape of the distribution. The vertical black line in each panel denotes the threshold at which the marginal tax rate changes in that year (the panel of the pre-treatment year 1995 shows the threshold of 1999).

The bin-to-bin jumps in the frequencies enable us to identify exceptional jumps at the threshold $c$ that indicate a discontinuity in the density. If firms could precisely manipulate their electricity use and thereby select themselves into the treatment group, we would expect a significant upward jump in the bins located directly right of the threshold.

The histograms do not provide any evidence that firms manipulated their electricity use. Figure 3 shows several upward jumps that are located far from the thresholds. However, directly right of the thresholds there are no unusual jumps that would indicate manipulation of electricity use.

Figure 4 shows a visualization of the discontinuity test developed by McCrary (2008) for the pre-treatment year 1995 and the treatment years 1999 - 2005. Each panel exhibits an estimate of the density function of the assignment variable electricity use and the corresponding 95 percent confidence interval. The density function is estimated 
Figure 3: Empirical distribution of electricity use near the threshold in 1995 and $1999-2005$.
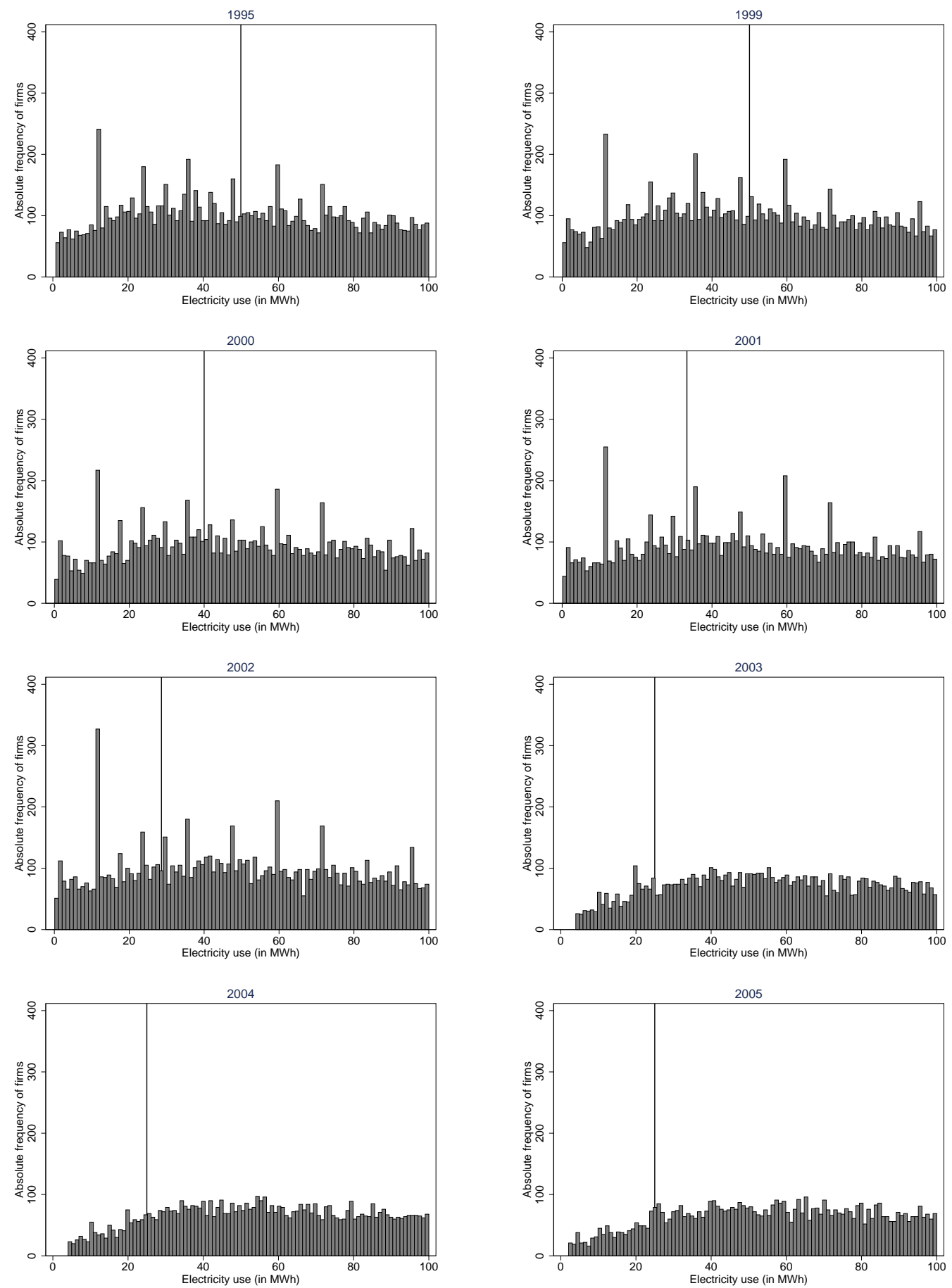

Notes: Source: Research Data Centres of the Statistical Offices Germany (2014): Official Firm Data for Germany (AFiD) - AFiD-Panel Industrial Units and AFiD-Module Use of Energy, own calculations. 
Figure 4: Visualization of the McCrary discontinuity test.
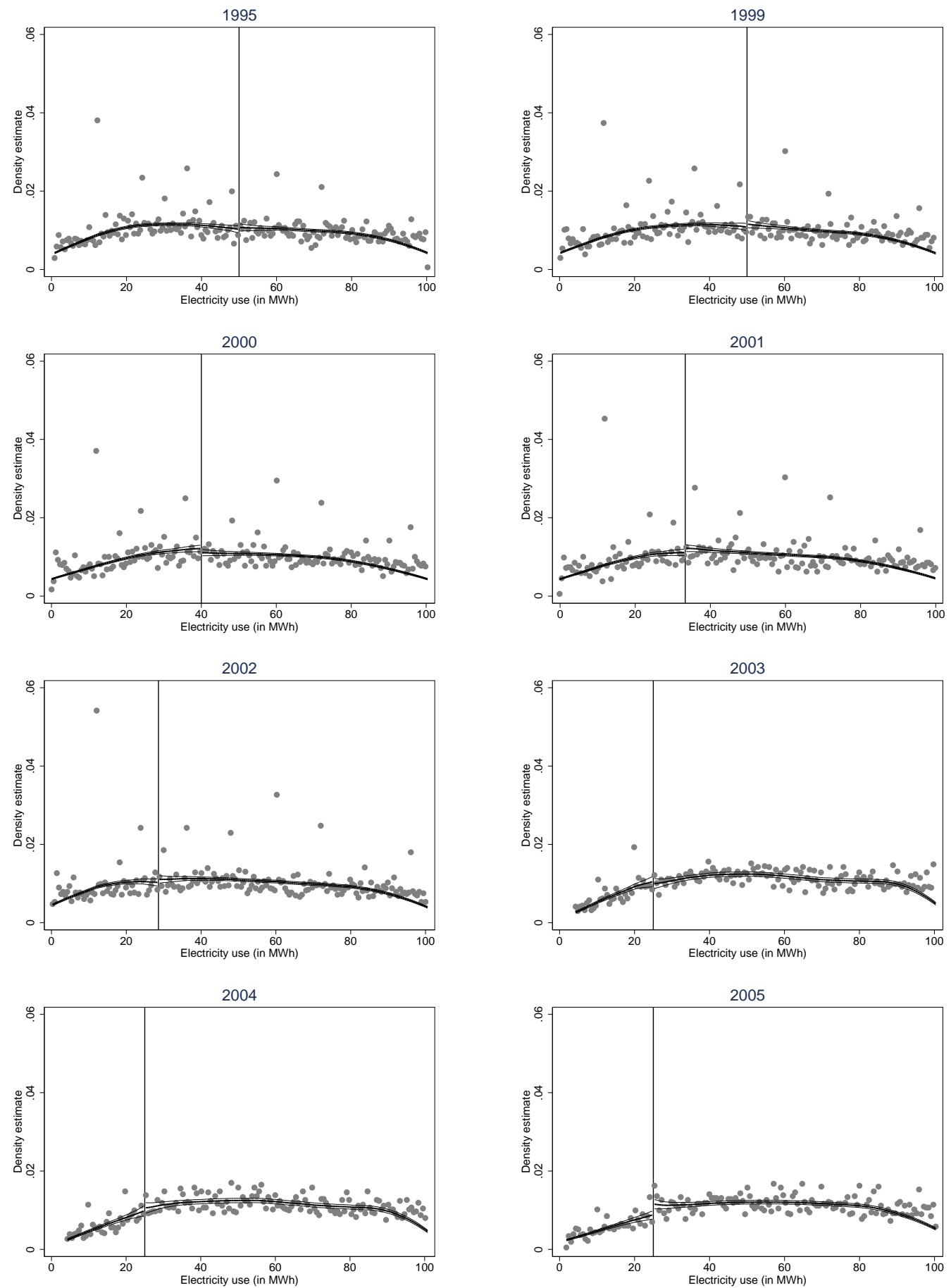

Notes: Source: Research Data Centres of the Statistical Offices Germany (2014): Official Firm Data for Germany (AFiD) - AFiD-Panel Industrial Units and AFiD-Module Use of Energy, own calculations. 
using the local linear density estimation technique proposed by McCrary (2008). The dots represent local densities for bins with a width between 0.50 and $0.75 \mathrm{MWh}$. The binwidths are calculated following the procedure in McCrary (2008).

Examining the point cloud, which gives a good visual impression of the empirical density function of the assignment variable, we do not see clear evidence for a discontinuity at the threshold in the pre-treatment year 1995 and in the treatment years 1999 - 2004. An inspection of the plotted density function and the corresponding confidence intervals lead to the same result. Only for the year 2005 the test shows that the density is significantly higher close to the right of the threshold suggesting a discontinuity at the threshold. Yet, looking at the absolute frequencies for the same year in Figure 3 reveals also excess mass close to the left of the threshold. In particular, the number of firms increases sharply at $24 \mathrm{MWh}$ electricity use. In comparison to the jumps and irregularities in the absolute frequencies further away from the threshold, there is seemingly a slight unsystematic jump in the frequencies between 24 and 27 MWh electricity use. The rejection of the null hypothesis of continuity in the framework of the test developed by McCrary (2008) may therefore be due to a unsystematic jump in the density rather than a systematic break in the density function. Also the graphs in Figure 4 show jumps in the local densities for all years, even at locations far away from the thresholds.

An alternative approach for investigating a potential sorting into the treatment group would be to examine, if continuous baseline covariates show discontinuities at the threshold. However, for firm data this approach is barely feasible, since one would need firm characteristics that are (i) continuous and (ii) unaffected by the treatment. A change in the relative input prices - e.g. through a tax - potentially leads to a change in input use as well as output production. All continuous variables in our data set hence might be affected by the electricity tax.

From 2003 onwards, the histograms as well as the density estimates show fewer firms in comparison to the years before. This phenomenon emerges mostly due to two methodological changes. First, due to the switch from the monthly to the yearly census, some firms were not surveyed in the years 2003 and 2004. Second, the classification by economic activity changed in 2003. Firms may have ascertained, if they were correctly classified, and reclassified if not. Consequently some firms that have not been in the manufacturing sector might have been reclassified.

Second, we investigate the assumption of local continuity, i.e., that the outcome variable evolves continuously around the threshold when the intervention is absent. Since we do not observe the counterfactual - firms that lie above the threshold and are not treated - we analyze the relationship of outcome and assignment variable before the intervention started. Figure 5 contains four scatter plots showing non-overlapping binned local means and second order global polynomial functions of the outcome variables turnover, exports, investment, and employment for the pre-treatment year 1995. The local means are computed for $1 \mathrm{MWh}$ bandwidths in the area of $25-75 \mathrm{MWh}$, the $c \pm 25 \mathrm{MWh}$ neighborhood of the $50 \mathrm{MWh}$ threshold that applies for the first year of the treatment 
Figure 5: Outcomes in the pre-treatment year 1995.
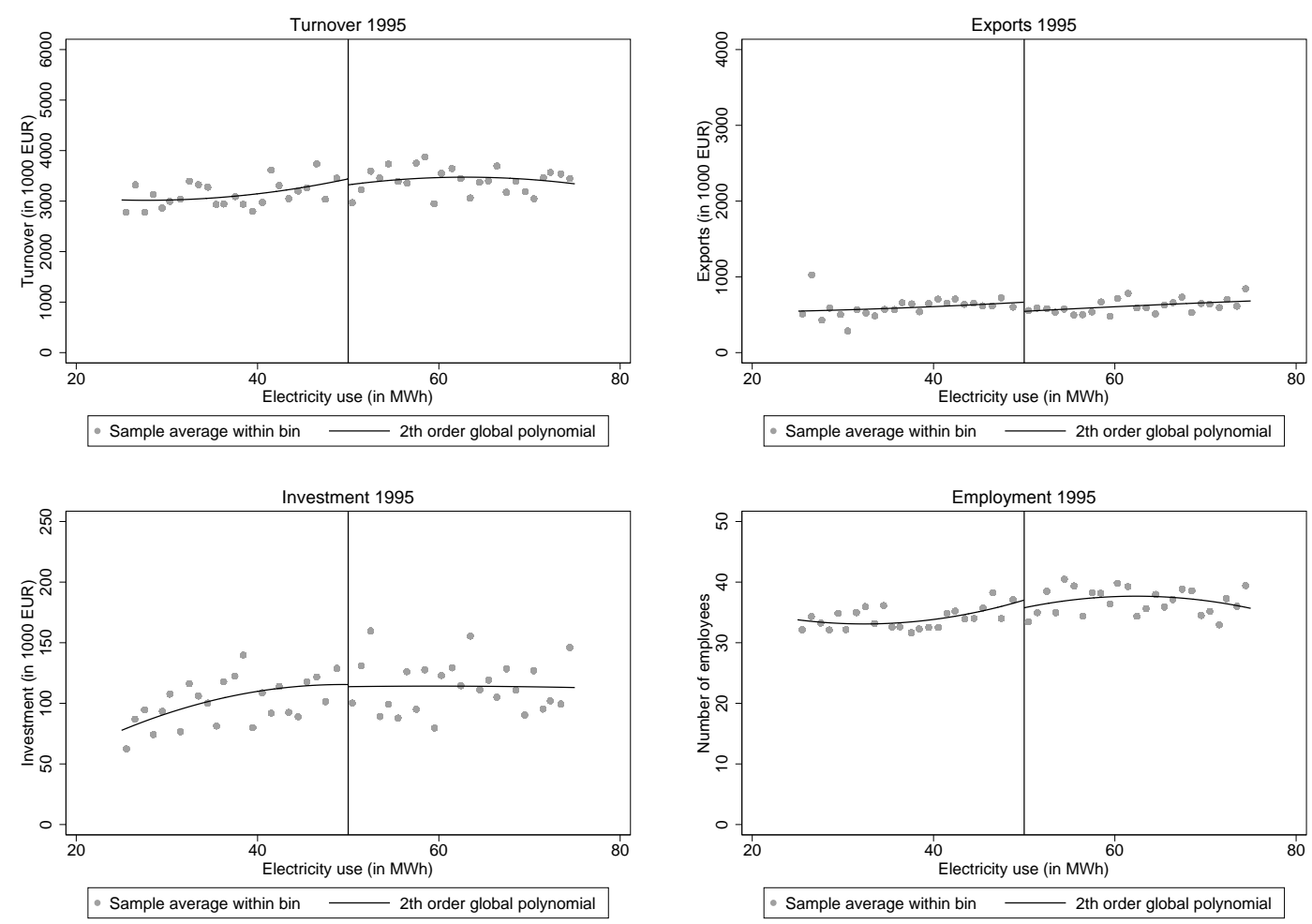

Notes: Source: Research Data Centres of the Statistical Offices Germany (2014): Official Firm Data for Germany (AFiD) - AFiD-Panel Industrial Units and AFiD-Module Use of Energy, own calculations.

1999. Neither the point cloud of binned local means, nor the second order polynomial give rise to concern that a discontinuity and thus a violation of the local continuity restriction is present.

\subsection{Graphical analysis}

We start our analysis by showing graphical evidence on the relationship between the outcome variables and the assignment variable electricity use. We compute local conditional sample averages for $1 \mathrm{MWh}$ non-overlapping bins of electricity use and also show estimates of second order global polynomial regression functions for either side of the threshold separately. The panels in the first column in Figure 6 show the results for four outcome variables: turnover, exports, investment, and employment in 2000. The panels in the second column show the results for the same variables in 2005 . The vertical black lines at $40 \mathrm{MWh}$ and $25 \mathrm{MWh}$ denote the thresholds for tax reductions. The plots are trimmed to the electricity use $c \pm 25 \mathrm{MWh}$ around the threshold.

Our aim is to discover discontinuities, or in other words shifts, in the local conditional sample averages. A shift at the threshold would indicate an effect of the tax reduction on the outcome variables. Shifts in regions away from the threshold would highlight the presence of other discontinuities and would question the applicability of the regression discontinuity design in this context. Note that the cloud of local conditional sample 
averages indicates the level of dispersion of the data.

The graphs depicted in Figure 6 do not show evidence for an obvious discontinuity at the threshold. A positive effect of the reduced tax rate on one of the outcome variables would be indicated by an upward shift to the right of the thresholds of both the binned averages and the regression lines. A negative effect on one of the outcome variables would be indicated by a downward shift to the right of the threshold of both the binned averages and the regression lines. Regarding the global polynomial functions, one should bear in mind that the estimates are less precise close to the thresholds than further away from them. A point estimated further away from the threshold can draw on additional information toward its right and left for estimation, while a point close to the threshold can only draw on additional information on one side. The small discontinuities in regression lines are thus likely due to less precise estimation at the thresholds than further away 9 A systematic shift of the regression lines or the cloud of binned local means indicating a discontinuity at the threshold is not observed.

For both turnover and investment, substantial heterogeneity is observed between the local sample averages reflecting the high degree of variance discussed in Section 4.3 . However, no discontinuity is found at the threshold. Also for exports, the local sample averages do not indicate a discontinuity at the threshold. However, the global polynomial function indicates a slight upward shift to the right of the threshold. This is seemingly driven by the four bins to the left of the threshold for the reduced tax rate at $25 \mathrm{MWh}$ and the five bins to the right of the threshold. Bins further away from the threshold do not show a consistent difference in average exports. No indication for a discontinuity at the threshold is found for employment, neither by the local sample averages nor by the global polynomical functions 10

Figure 7 shows the impact of the reduced electricity tax on value added. Information on value added is only available from a mandatory survey of firms. Thereby there are less observations than for the outcome variables above that originate from a census of firms. The dispersion of value added is lower than that of turnover or exports as also shown in the descriptive statistics in Section 4.3 . This translates into a fairly smooth relationship between value added and electricity use and may help to detect a potential discontinuity at the threshold. However, neither the binned conditional sample averages nor the global polynomial regression functions indicate an effect of the reduced electricity tax on value added.

In addition, the plots do not provide evidence for discontinuities away from the threshold. Hence there is no indication of other sources that may cause discontinuities

\footnotetext{
${ }^{9}$ For the estimation of the local average treatment effect in the following section we rely on the nonparametric approach based on weighted local linear regressions on both sides of the threshold proposed by Hahn, Todd, and van der Klaauw (2001) and Porter (2003) in order to mitigate this problem. The estimator shows good small sample properties and is suitable for inference at the boundary of the support of the regression function.

${ }^{10}$ The observed pattern for the years 2000 and 2005 also hold for other years in which the reduced tax rate applied. Results are available upon request.
} 
Figure 6: Discontinuity effect of the reduction on the marginal tax rate I.
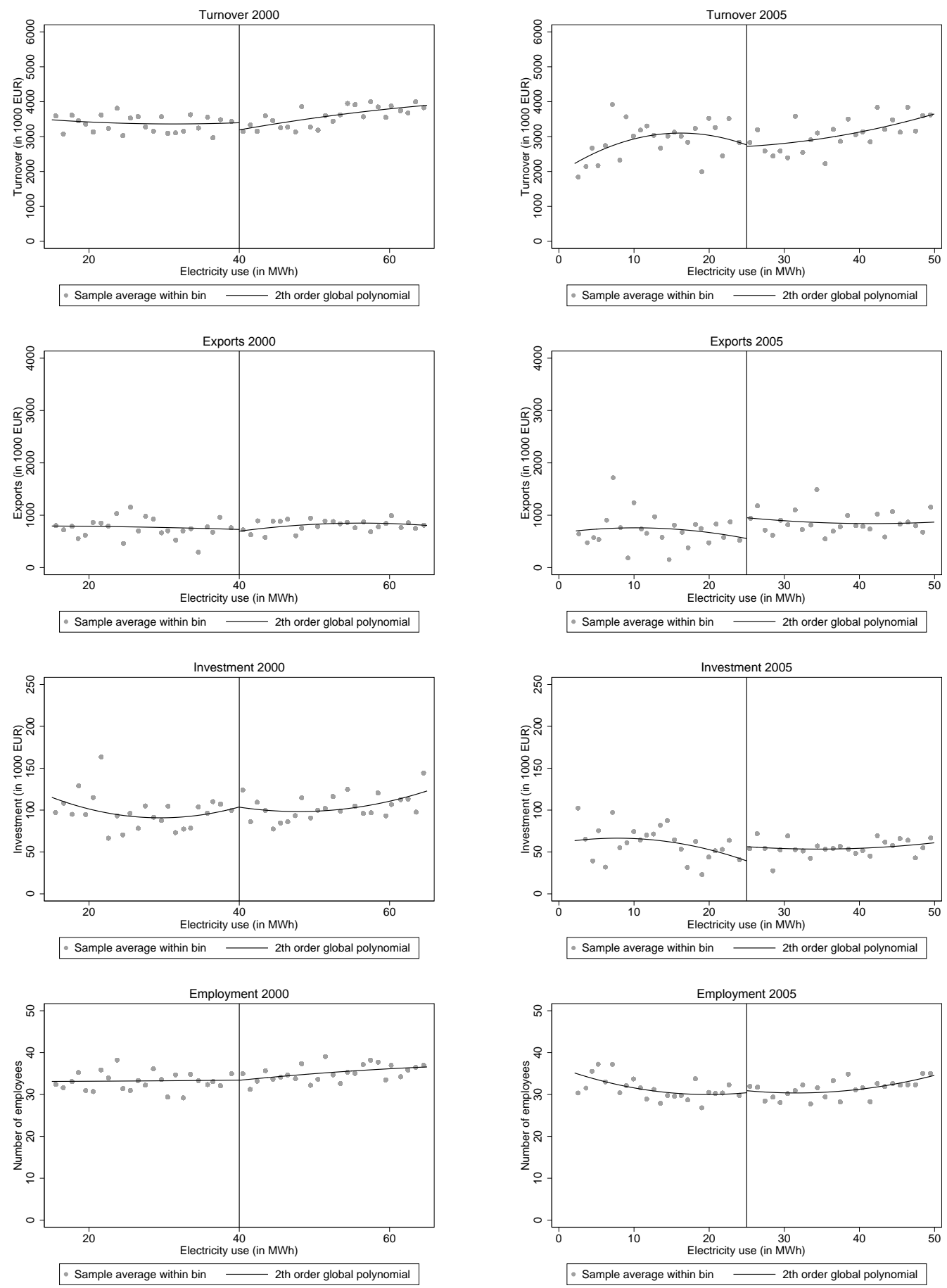

Notes: Assignment variable: electricity use. Outcome variables: turnover, exports, investment, and employment. Source: Research Data Centres of the Statistical Offices Germany (2014): Official Firm Data for Germany (AFiD) - AFiD-Panel Industrial Units and AFiD-Module Use of Energy, own calculations. 
Figure 7: Discontinuity effect of the reduction on the marginal tax rate II.
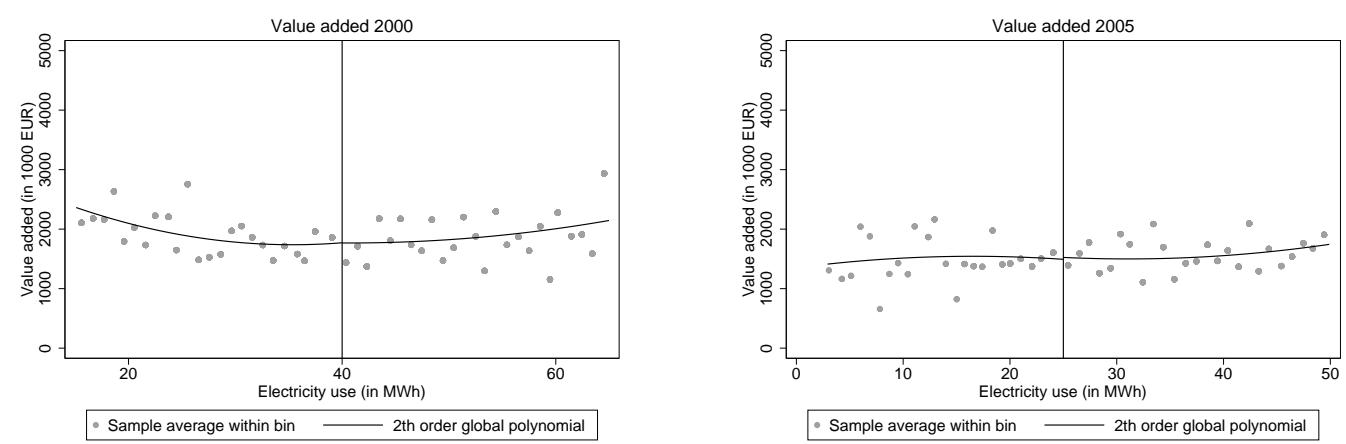

Notes: Assignment variable: electricity use. Outcome variable: value added. Source: Research Data Centres of the Statistical Offices Germany (2014): Official Firm Data for Germany (AFiD) - AFiD-Panel Industrial Units, AFiD-Module Use of Energy, and Cost Structure Survey, own calculations.

in the relationships between outcome variables and assignment variable.

\subsection{Local treatment effects}

In this section we present the estimated local average treatment effects of the tax reduction scheme on the outcome variables turnover, exports, investment, employment, and value added. Being precise, we estimate the effect of the difference between the full and the reduced marginal tax rate - i.e. the reduction of the marginal tax rate. The firms that consume more electricity than the threshold $c$ benefit from a lower marginal tax rate and form the treatment group. The firms that consume less electricity than the threshold $c$ face the full marginal tax rate and thus denote the control group. A year by year evaluation leads to seven experiments and 35 treatment effects of interest in the years 1999-2005.

The estimators of the local average treatment effects presented in the following are computed as described in Section 3.3 . Recall, that the estimators of the local average treatment effects are computed as the difference of the constants of two weighted linear regressions for narrow bandwidths left and right of the threshold. Here, the weights for linear regression are computed based on a triangular kernel function. ${ }^{11}$ The bandwidths are computed based on the data-driven bandwidth selection procedure developed by Imbens and Kalyanaraman (2012).

In Table 3 we show the estimated effects of the tax reduction for each year in the period 1999 - 2005 along with the characteristics of the prevailing tax scheme. In each experiment we consider observations in the neighborhood $c \pm 25 \mathrm{MWh}$ around the threshold. Outliers of the outcome variables are removed outside the $1^{\text {st }}$ and $99^{\text {th }}$ percentile. The left panel of Table 3 summarizes the information on the electricity tax. It shows for each year the full tax rate as well as the thresholds from which the reduced marginal

\footnotetext{
${ }^{11}$ The results do not systematically change when using alternative kernel functions. Table 8 and 9 in Annex B report the results of the local average treatment effect estimation considering uniform and Epanechnikov kernel functions.)
} 
Table 3: Local treatment effects.

\begin{tabular}{|c|c|c|c|c|c|c|c|c|}
\hline \multirow[b]{2}{*}{ Year } & \multicolumn{3}{|c|}{ Tax reduction scheme } & \multicolumn{5}{|c|}{ Effect of reduced marginal tax rate } \\
\hline & $\begin{array}{l}\text { Threshold } \\
\text { (MWh) }\end{array}$ & $\begin{array}{l}\text { Full } \\
\text { tax rate } \\
(\text { EUR/MWh) }\end{array}$ & $\begin{array}{l}\text { Tax re- } \\
\text { duction } \\
\text { (EUR/MWh) }\end{array}$ & Turnover & Exports & $\begin{array}{l}\text { Invest- } \\
\text { ment }\end{array}$ & $\begin{array}{l}\text { Employ- } \\
\text { ment }\end{array}$ & $\begin{array}{l}\text { Value } \\
\text { added }\end{array}$ \\
\hline 1999 & 50 & 10 & 8 & $\begin{array}{l}95.40 \\
(169.85)\end{array}$ & $\begin{array}{l}2.01 \\
(108.37)\end{array}$ & $\begin{array}{l}-10.50 \\
(11.24)\end{array}$ & $\begin{array}{l}-0.39 \\
(0.99)\end{array}$ & $\begin{array}{l}-83.75 \\
(199.12)\end{array}$ \\
\hline 2000 & 40 & 12.5 & 10 & $\begin{array}{l}-166.78 \\
(180.53)\end{array}$ & $\begin{array}{l}-36.53 \\
(108.98)\end{array}$ & $\begin{array}{l}-1.73 \\
(11.54)\end{array}$ & $\begin{array}{l}-0.12 \\
(1.17)\end{array}$ & $\begin{array}{l}-18.67 \\
(200.28)\end{array}$ \\
\hline 2001 & 33 & 15 & 12 & $\begin{array}{l}440.78^{*} \\
(216.96)\end{array}$ & $\begin{array}{l}-180.18 \\
(121.50)\end{array}$ & $\begin{array}{l}9.36 \\
(9.80)\end{array}$ & $\begin{array}{l}-0.62 \\
(0.96)\end{array}$ & $\begin{array}{l}183.14 \\
(208.51)\end{array}$ \\
\hline 2002 & 28.6 & 17.9 & 14.6 & $\begin{array}{l}-379.65 \\
(238.68)\end{array}$ & $\begin{array}{l}-47.27 \\
(108.33)\end{array}$ & $\begin{array}{l}-20.65^{*} \\
(10.29)\end{array}$ & $\begin{array}{l}0.16 \\
(1.13)\end{array}$ & $\begin{array}{l}-492.54 \\
(299.71)\end{array}$ \\
\hline 2003 & 25 & 20.5 & 8.2 & $\begin{array}{l}-136.42 \\
(221.77)\end{array}$ & $\begin{array}{l}-232.44 \\
(156.74)\end{array}$ & $\begin{array}{l}-4.18 \\
(8.43)\end{array}$ & $\begin{array}{l}-0.49 \\
(1.33)\end{array}$ & $\begin{array}{l}-177.09 \\
(181.25)\end{array}$ \\
\hline 2004 & 25 & 20.5 & 8.2 & $\begin{array}{l}254.35 \\
(216.70)\end{array}$ & $\begin{array}{l}-48.75 \\
(157.89)\end{array}$ & $\begin{array}{l}-4.41 \\
(9.00)\end{array}$ & $\begin{array}{l}0.72 \\
(1.04)\end{array}$ & $\begin{array}{l}83.51 \\
(203.20)\end{array}$ \\
\hline 2005 & 25 & 20.5 & 8.2 & $\begin{array}{l}-106.73 \\
(268.37)\end{array}$ & $\begin{array}{l}335.86^{*} \\
(164.23)\end{array}$ & $\begin{array}{l}14.48 \\
(7.88)\end{array}$ & $\begin{array}{l}0.59 \\
(1.32)\end{array}$ & $\begin{array}{l}-35.59 \\
(213.67)\end{array}$ \\
\hline
\end{tabular}

Notes: * indicates significance at the 5 percent level. Standard errors are shown in parentheses. Analysis covers firms in the $\pm 25 \mathrm{MWh}$ region around the threshold. The order of the polynomial function is set to 1 . Source: Research Data Centres of the Statistical Offices Germany (2014): Official Firm Data for Germany (AFiD) AFiD-Panel Industrial Units, AFiD-Module Use of Energy, and Cost Structure Survey, own calculations.

tax rate applies and the difference between the full marginal tax rate. The right panel shows the point estimates of the regression discontinuity analysis and the corresponding standard errors.

The thirty-two statistically non-significant effects in Table 3 clearly outweigh the three statistically significant effects. These statistical significant effects indicate a positive impact of the tax reduction on turnover in 2001 and exports in 2005 as well as a negative effect on investment in 2002.

Table 4 shows the bandwidth choice for each experiment as well as the number of observations that lie within the bandwidths right and left of the threshold. The selected bandwidths lie in a range between 15 and $25 \mathrm{MWh}$. The selected bandwidths for exports are typically smaller and thereby have fewer observations than those for turnover, investment and employment.

The results from the regression discontinuity analysis indicate hardly any evidence for a consistent effect of the reduced marginal electricity tax on turnover, exports, investment, employment, or gross value added. First, there is only a low number of statistically significant treatment effects (only three out of thirty-five) that might result from statistical error. Second, there is no consistent pattern of negative or positive signs for the local treatment effects. Neither have the three statistically significant effects the same sign nor do the five dependent variables show a particular pattern or trend 12

\footnotetext{
${ }^{12}$ To investigate robustness with regard to distributional assumptions and outliers, we estimated a log specification of our model. The qualitative findings do not change. Detailed results are available upon request.
} 
Table 4: Imbens and Kalyanaraman (2012) bandwidths and number of observations.

\begin{tabular}{|c|c|c|c|c|}
\hline \multirow[t]{2}{*}{ Outcome variable } & \multirow[t]{2}{*}{ Bandwidth } & \multicolumn{3}{|c|}{ Number of observations } \\
\hline & & $\mathrm{c} \pm 25 \mathrm{MWh}$ & Control group & Treatment group \\
\hline \multicolumn{5}{|l|}{ Panel A: 1999} \\
\hline Turnover & 24.15 & 5,289 & 2,671 & 2,442 \\
\hline Exports & 16.11 & 2,330 & 755 & 793 \\
\hline Investment & 22.89 & 3,873 & 1,848 & 1,739 \\
\hline Employment & 23.42 & 5,289 & 2,615 & 2,377 \\
\hline Value added & 21.30 & 1,452 & 661 & 600 \\
\hline \multicolumn{5}{|l|}{ Panel B: 2000} \\
\hline Turnover & 22.38 & 5,017 & 2,306 & 2,263 \\
\hline Exports & 18.47 & 2,137 & 772 & 815 \\
\hline Investment & 19.07 & 3,691 & 1,487 & 1,397 \\
\hline Employment & 19.34 & 5,014 & 2,023 & 1,877 \\
\hline Value added & 20.17 & 1,301 & 536 & 546 \\
\hline \multicolumn{5}{|l|}{ Panel C: 2001} \\
\hline Turnover & 16.61 & 4,862 & 1,557 & 1,769 \\
\hline Exports & 18.03 & 2,041 & 647 & 842 \\
\hline Investment & 17.48 & 3,338 & 1,095 & 1,302 \\
\hline Employment & 25.00 & 4,859 & 2,339 & 2,520 \\
\hline Value added & 20.35 & 1,119 & 413 & 495 \\
\hline \multicolumn{5}{|l|}{ Panel D: 2002 } \\
\hline Turnover & 14.01 & 5,072 & 1,323 & 1,511 \\
\hline Exports & 18.07 & 2,114 & 758 & 819 \\
\hline Investment & 20.85 & 3,360 & 1,316 & 1,572 \\
\hline Employment & 20.32 & 5,063 & 2,047 & 2,216 \\
\hline Value added & 22.37 & 985 & 377 & 510 \\
\hline \multicolumn{5}{|l|}{ Panel E: 2003} \\
\hline Turnover & 16.28 & 3,052 & 891 & 1,294 \\
\hline Exports & 12.74 & 1,290 & 278 & 407 \\
\hline Investment & 18.35 & 2,175 & 650 & 1,076 \\
\hline Employment & 18.97 & 3,052 & 964 & 1,537 \\
\hline Value added & 16.36 & 851 & 249 & 362 \\
\hline \multicolumn{5}{|l|}{ Panel F: 2004} \\
\hline Turnover & 14.08 & 2,779 & 657 & 1,079 \\
\hline Exports & 14.44 & 1,138 & 236 & 466 \\
\hline Investment & 17.44 & 1,979 & 553 & 960 \\
\hline Employment & 18.44 & 2,778 & 798 & 1,414 \\
\hline Value added & 15.82 & 704 & 172 & 319 \\
\hline \multicolumn{5}{|l|}{ Panel G: 2005} \\
\hline Turnover & 12.22 & 2,654 & 535 & 843 \\
\hline Exports & 17.12 & 1,068 & 266 & 479 \\
\hline Investment & 17.36 & 1,856 & 495 & 870 \\
\hline Employment & 12.78 & 2,654 & 559 & 886 \\
\hline Value added & 23.17 & 621 & 177 & 408 \\
\hline
\end{tabular}

Notes: Turnover, investment and exports are denoted in EUR 1000. The number of observations refer to the $\pm 25 \mathrm{MWh}$ region around the threshold c. The bandwidth is selected based on the procedure in Imbens and Kalyanaraman (2012). Source: Research Data Centres of the Statistical Offices Germany (2014): Official Firm Data for Germany (AFiD) - AFiD-Panel Industrial Units, AFiD-Module Use of Energy, and Cost Structure Survey, own calculations. 


\subsection{Sensitivity toward bandwidth choice}

In this section, we investigate the sensitivity of our findings toward different bandwidths. The results in the previous section do not show any systematic significant effects of the reduced tax rates on economic outcomes. The question in the following paragraphs is whether these results are robust for various choices of bandwidth.

Bandwidth choice is a choice between precision and bias. Larger bandwidths offer more precise estimates as they can rely on a larger number of observations. At the same time larger bandwidths may generate bias, in particular when using a linear estimator for data that is inherently nonlinear. The optimal bandwidth that minimizes the mean squared error decreases with the number of observations. The bandwidths chosen in the previous section are derived by applying a fully data driven and asymptotically optimal bandwidth choice as developed by Imbens and Kalyanamaran (2012).

Given the above tradeoffs between precision and bias, we present results across different integer bandwidth choices ranging from 5 to $25 \mathrm{MWh}$ in Figure 8 for the years 2000 and 2005. The solid black line in each panel denotes point estimates and the dashed lines are corresponding 95 percent confidence intervals. The standard errors decrease with increasing bandwidths as expected. In most cases also the estimates become smaller in absolute terms and approach zero with increasing bandwidths, without becoming statistically significant. This confirms our previous findings that do not indicate any effects of the reduced tax rates on economic outcomes. Smaller bandwidths tend to have larger point estimates. Given the higher imprecision of the estimates, no point estimate is significant for bandwidths below $16 \mathrm{MWh}$, adding to the evidence that there is no significant effect.

In addition we note that the observed patterns for 2000 and 2005 hold for the other years too. Table 10 in Appendix $\mathrm{C}$ reports the results of the local average treatment estimation for the bandwidths 5, 10, 15, 20, and 25 in 1999-2005. The significant positive local average treatment effect on turnover in 2001 seems not to depend on bandwidth choice. Yet, the significant negative estimate for investment in 2002 is not robust to bandwidth choice. It is only significant for a bandwidth between 10 and 20 MWh. Figure 11 in Appendix C shows the point estimates and 95 percent confidence intervals across different integer bandwidth choices for turnover in 2001 and investment in 2002 analogous to Figure 8 previously.

\subsection{Sensitivity toward polynomial choice}

In addition to selecting the bandwidth, the choice of the polynomial order may also affect results. Choosing a local linear estimator for data that is inherently non-linear may bias results, in particular when the bandwidth is large. While Figure6 6 in Section 5.2 might suggest that higher order global polynomial estimators fit best for some outcome variables in some years, it also does not point toward strong local non-linearities in the data. This visual inspection may therefore suggest that the previously chosen local linear 
Figure 8: The effect of bandwidth choice on point estimates and confidence intervals.
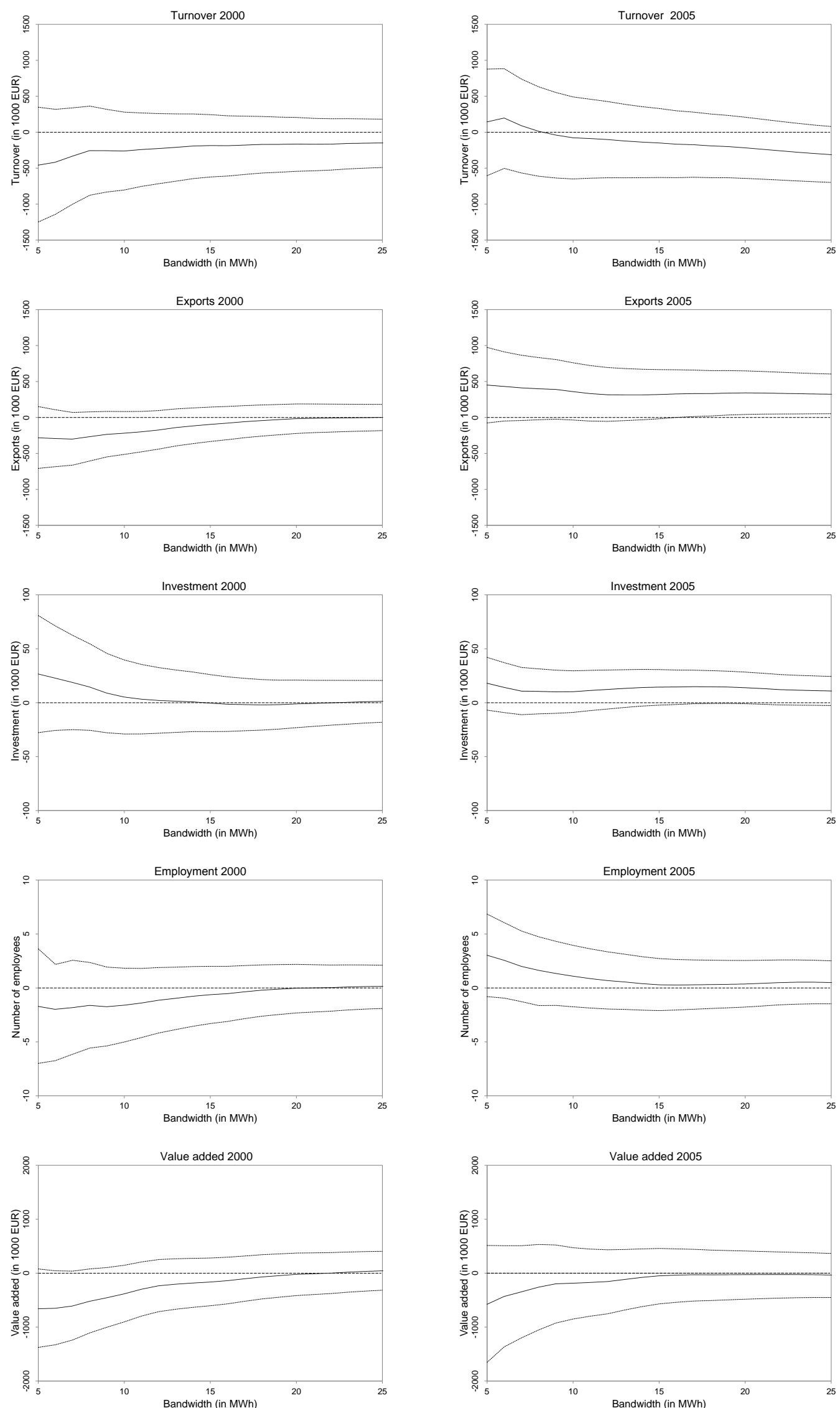

Notes: The solid black line in each panel denotes point estimates and the dashed lines are corresponding 95 percent confidence intervals. Source: Research Data Centres of the Statistical Offices Germany (2014): Official Firm Data for Germany (AFiD) - AFiD-Panel Industriæ6Units, AFiD-Module Use of Energy, and Cost Structure Survey, own calculations. 
regressions should not suffer from substantial bias.

An additional robustness check with a higher order polynomial does not change the previous findings, confirming as well that the local linear regressions are not substantially biased. Table 5 shows the results for the effect of the reduced tax rate on economic outcomes applying local quadratic polynomial regressions. The bandwidths are optimally selected using the procedure developed by applying Imbens and Kalyanamaran (2012) as previously. While many point estimates increase somewhat confidence intervals also increase substantially. This results in only three out of 35 estimates becoming statistically significant. As previously there is also no pattern regarding the signs of the effects, confirming that there are no consistent effects of the reduced tax rates on economic outcomes.

Given the fairly linear underlying data close to the threshold, results would unlikely change with higher polynomial orders. The underlying data nevertheless reveals a fair amount of heterogeneity as both shown in Figure 6 and the descriptive statistics. The following section therefore investigates how this heterogeneity may impact our results.

\subsection{Treatment effects across industries}

The aim of this section is twofold. First, we shed light onto the robustness of our results with respect to heterogeneity across industries within the manufacturing sector. For this purpose, we analyze the effect of the electricity tax reduction on firms of different subpopulations. Second, we aim to examine the effect of the electricity tax reduction on an energy intensive industry. If the electricity tax reduction has no impact on firms of an industry that is particularly affected by higher electricity prices, this would add additional support to our findings in the previous sections.

Industries within manufacturing differ along many dimensions. These differences concern - among other things - the output they produce, the technologies they deploy, or the market and industry structures they face. As a consequence, the treatment effect of the electricity tax reduction may vary across industries or subsectors. If effects have different signs for different groups, this might lead to an insignificant average treatment effect for the whole population. In addition, effects are only significant for a small subpopulation that is energy intensive, this might not show up in the average treatment effect for the whole population of firms.

The first subpopulation we investigate are firms that manufacture machinery, electronic devices, and vehicles 13 This subpopulation is chosen as it consist of more homogenous firms, namely those that manufacture machinery, electronic devices, and vehicles compared to all other types of goods, and at the same time still comprises a sufficient

\footnotetext{
${ }^{13}$ According to ISIC Rev. 3.1: manufacture of machinery and equipment n.e.c. (29), manufacture of office, accounting, and computing machinery (30), manufacture of electrical machinery and apparatus n.e.c. (31), manufacture of radio, television, and communication equipment and apparatus (32), manufacture of medical, precision and optical instruments, watches and clocks (33), manufacture of motor vehicles, trailers, and semi-trailers (34), manufacture of other transport equipment (35)
} 
Table 5: The effect of an alternative polynomial order.

\begin{tabular}{|c|c|c|c|c|c|}
\hline \multirow[t]{2}{*}{ Outcome variable } & \multirow[t]{2}{*}{ Estimator } & \multirow[t]{2}{*}{ Bandwidth } & \multicolumn{3}{|c|}{ Number of observations } \\
\hline & & & $\mathrm{c} \pm 25 \mathrm{MWh}$ & Control group & Treatment group \\
\hline \multicolumn{6}{|l|}{ Panel A: 1999} \\
\hline Turnover & $163.50(238.29)$ & 23.43 & 5,289 & 2,606 & 2,387 \\
\hline Exports & $-77.66(144.47)$ & 19.93 & 2,330 & 901 & 965 \\
\hline Investment & $-9.45(15.91)$ & 23.41 & 3,873 & 1,883 & 1,770 \\
\hline Employment & $-0.62(1.41)$ & 21.19 & 5,289 & 2,375 & 2,124 \\
\hline Value added & $-157.62(291.27)$ & 18.83 & 1,452 & 589 & 540 \\
\hline \multicolumn{6}{|l|}{ Panel B: 2000} \\
\hline Turnover & $-241.09(282.45)$ & 20.39 & 5,017 & 2,118 & 2,069 \\
\hline Exports & $-196.71(153.00)$ & 21.03 & 2,137 & 854 & 972 \\
\hline Investment & $-0.93(17.01)$ & 21.72 & 3,691 & 1,615 & 1,636 \\
\hline Employment & $-1.72(1.86)$ & 18.75 & 5,014 & 1,976 & 1,834 \\
\hline Value added & $-331.80(272.04)$ & 21.07 & 1,301 & 550 & 568 \\
\hline \multicolumn{6}{|l|}{ Panel C: 2001} \\
\hline Turnover & $580.77^{*}(286.41)$ & 21.22 & 4,862 & 1,915 & 2,197 \\
\hline Exports & $-182.94(177.07)$ & 17.71 & 2,041 & 639 & 825 \\
\hline Investment & $7.76(12.49)$ & 21.91 & 3,338 & 1,437 & 1,607 \\
\hline Employment & $0.30(1.49)$ & 22.27 & 4,859 & 2,164 & 2,294 \\
\hline Value added & $-368.42(272.01)$ & 21.87 & 1,119 & 466 & 532 \\
\hline \multicolumn{6}{|l|}{ Panel D: 2002} \\
\hline Turnover & $-430.40(266.11)$ & 24.35 & 5,072 & 2,335 & 2,628 \\
\hline Exports & $-65.91(135.57)$ & 29.34 & 2,114 & 910 & 1,204 \\
\hline Investment & $-27.84 *(13.49)$ & 28.42 & 3,360 & 1,514 & 1,846 \\
\hline Employment & $-0.63(1.58)$ & 23.32 & 5,063 & 2,264 & 2,535 \\
\hline Value added & $-911.67 *(448.78)$ & 21.69 & 985 & 367 & 495 \\
\hline \multicolumn{6}{|l|}{ Panel E: 2003} \\
\hline Turnover & $41.90(323.79)$ & 16.66 & 3,052 & 899 & 1,329 \\
\hline Exports & $-357.13(215.91)$ & 15.66 & 1,290 & 333 & 529 \\
\hline Investment & $2.08(11.82)$ & 19.23 & 2,175 & 664 & 1,136 \\
\hline Employment & $1.16(2.12)$ & 16.60 & 3,052 & 888 & 1,330 \\
\hline Value added & $-134.90(269.32)$ & 14.58 & 851 & 232 & 318 \\
\hline \multicolumn{6}{|l|}{ Panel F: 2004} \\
\hline Turnover & $420.63(274.62)$ & 17.46 & 2,779 & 776 & 1,345 \\
\hline Exports & $-112.14(231.50)$ & 15.07 & 1,138 & 251 & 490 \\
\hline Investment & $-1.15(12.77)$ & 20.36 & 1,979 & 600 & 1,120 \\
\hline Employment & $2.81(1.46)$ & 18.53 & 2,778 & 802 & 1,420 \\
\hline Value added & $107.21(292.40)$ & 21.79 & 704 & 202 & 441 \\
\hline \multicolumn{6}{|l|}{ Panel G: 2005} \\
\hline Turnover & $-29.45(319.81)$ & 17.54 & 2,654 & 718 & 1,256 \\
\hline Exports & $334.83(224.97)$ & 17.00 & 1,068 & 264 & 473 \\
\hline Investment & $11.09(10.77)$ & 17.80 & 1,856 & 498 & 891 \\
\hline Employment & $0.33(1.47)$ & 21.73 & 2,654 & 808 & 1,566 \\
\hline Value added & $-167.17(355.19)$ & 20.39 & 621 & 170 & 354 \\
\hline
\end{tabular}

Notes: * indicates significance at the 5 percent level. Standard errors are shown in parentheses. Turnover, investment and exports are denoted in EUR 1000. The number of observations refer to the $\pm 25 \mathrm{MWh}$ region around the threshold c. The bandwidth is selected based on the procedure in Imbens and Kalyanaraman (2012). Source: Research Data Centres of the Statistical Offices Germany (2014): Official Firm Data for Germany (AFiD) - AFiD-Panel Industrial Units, AFiD-Module Use of Energy, and Cost Structure Survey own calculations. 
Table 6: Sub sample analysis: manufacture of machinery, electronic devices, and vehicles.

\begin{tabular}{|c|c|c|c|c|c|}
\hline \multirow[t]{2}{*}{ Outcome variable } & \multirow[t]{2}{*}{ Estimator } & \multirow[t]{2}{*}{ Bandwidth } & \multicolumn{3}{|c|}{ Number of observations } \\
\hline & & & $\mathrm{c} \pm 25 \mathrm{MWh}$ & Control group & Treatment group \\
\hline \multicolumn{6}{|l|}{ Panel A: 1999} \\
\hline Turnover & $31.18(348.01)$ & 16.60 & 2,078 & 740 & 666 \\
\hline Exports & $-38.12(162.85)$ & 24.40 & 1,139 & 538 & 584 \\
\hline Investment & $-0.47(18.36)$ & 19.71 & 1,628 & 669 & 613 \\
\hline Employment & $-0.84(1.73)$ & 16.31 & 2,078 & 727 & 645 \\
\hline \multicolumn{6}{|l|}{ Panel B: 2000} \\
\hline Turnover & $-203.59(293.47)$ & 23.29 & 1,986 & 925 & 956 \\
\hline Exports & $-254.12(191.07)$ & 18.74 & 1,067 & 372 & 423 \\
\hline Investment & $-15.14(26.36)$ & 13.51 & 1,570 & 447 & 446 \\
\hline Employment & $-2.77(2.04)$ & 17.85 & 1,986 & 742 & 703 \\
\hline \multicolumn{6}{|l|}{ Panel C: 2001} \\
\hline Turnover & $-69.31(354.97)$ & 15.47 & 1,939 & 590 & 699 \\
\hline Exports & $-292.90(229.47)$ & 14.99 & 997 & 264 & 364 \\
\hline Investment & $-3.04(15.82)$ & 15.35 & 1,473 & 447 & 534 \\
\hline Employment & $-2.89(2.46)$ & 14.02 & 1,939 & 532 & 616 \\
\hline \multicolumn{6}{|l|}{ Panel D: 2002} \\
\hline Turnover & $-496.64(332.78)$ & 18.16 & 2,095 & 749 & 847 \\
\hline Exports & $-220.27(224.59)$ & 14.61 & 1,061 & 269 & 348 \\
\hline Investment & $-25.61(16.73)$ & 16.29 & 1,522 & 425 & 571 \\
\hline Employment & $1.14(2.27)$ & 20.07 & 2,094 & 794 & 960 \\
\hline \multicolumn{6}{|l|}{ Panel E: 2003} \\
\hline Turnover & $-267.88(413.95)$ & 13.38 & 1,342 & 328 & 443 \\
\hline Exports & $-68.16(264.04)$ & 15.50 & 677 & 176 & 260 \\
\hline Investment & $7.37(13.05)$ & 15.45 & 1,008 & 274 & 391 \\
\hline Employment & $1.50(3.14)$ & 12.02 & 1,341 & 292 & 393 \\
\hline \multicolumn{6}{|l|}{ Panel F: 2004} \\
\hline Turnover & $255.51(318.39)$ & 15.64 & 1,273 & 319 & 554 \\
\hline Exports & $32.12(336.48)$ & 14.92 & 611 & 130 & 242 \\
\hline Investment & $-6.62(11.40)$ & 14.92 & 981 & 222 & 404 \\
\hline Employment & $0.31(1.79)$ & 20.15 & 1,273 & 362 & 718 \\
\hline \multicolumn{6}{|l|}{ Panel G: 2005} \\
\hline Turnover & $684.84(423.16)$ & 9.13 & 1,253 & 193 & 312 \\
\hline Exports & $682.02 *(307.40)$ & 16.47 & 566 & 129 & 237 \\
\hline Investment & $8.81(10.94)$ & 20.00 & 947 & 269 & 504 \\
\hline Employment & $1.62(2.20)$ & 15.36 & 1,253 & 300 & 518 \\
\hline
\end{tabular}

Notes: * indicates significance at the 5 percent level. Standard errors are shown in parentheses. Turnover, investment and exports are denoted in EUR 1000. The number of observations refer to the $\pm 25 \mathrm{MWh}$ region around the threshold c. The bandwidth is selected based on the procedure in Imbens and Kalyanaraman (2012). Source: Research Data Centres of the Statistical Offices Germany (2014): Official Firm Data for Germany (AFiD) - AFiD-Panel Industrial Units, AFiD-Module Use of Energy, and Cost Structure Survey, own calculations. 
Table 7: Sub sample analysis: manufacture of basic metal and fabricated metal poducts.

\begin{tabular}{|c|c|c|c|c|c|}
\hline \multirow[t]{2}{*}{ Outcome variable } & \multirow[t]{2}{*}{ Estimator } & \multirow[t]{2}{*}{ Bandwidth } & \multicolumn{3}{|c|}{ Number of observations } \\
\hline & & & $\mathrm{c} \pm 25 \mathrm{MWh}$ & Control group & Treatment group \\
\hline \multicolumn{6}{|l|}{ Panel A: 1999} \\
\hline Turnover & $-49.29(381.28)$ & 13.26 & 885 & 248 & 227 \\
\hline Exports & $-69.52(137.62)$ & 23.06 & 260 & 109 & 135 \\
\hline Investment & $2.42(22.57)$ & 25.50 & 707 & 381 & 326 \\
\hline Employment & $-1.72(3.11)$ & 18.05 & 885 & 365 & 291 \\
\hline \multicolumn{6}{|l|}{ Panel B: 2000} \\
\hline Turnover & $-792.25(420.74)$ & 14.46 & 919 & 293 & 244 \\
\hline Exports & $-66.03(166.28)$ & 12.57 & 234 & 47 & 71 \\
\hline Investment & $-18.87(23.33)$ & 14.87 & 701 & 240 & 187 \\
\hline Employment & $-2.85(3.58)$ & 16.55 & 919 & 348 & 278 \\
\hline \multicolumn{6}{|l|}{ Panel C: 2001} \\
\hline Turnover & $81.81(447.33)$ & 13.73 & 932 & 265 & 264 \\
\hline Exports & $-75.62(110.28)$ & 15.33 & 226 & 55 & 79 \\
\hline Investment & $-6.67(18.90)$ & 15.85 & 642 & 206 & 214 \\
\hline Employment & $-3.75(3.50)$ & 9.36 & 932 & 195 & 190 \\
\hline \multicolumn{6}{|l|}{ Panel D: 2002 } \\
\hline Turnover & $97.90(378.42)$ & 22.94 & 956 & 450 & 438 \\
\hline Exports & $41.45(157.28)$ & 16.23 & 226 & 64 & 80 \\
\hline Investment & $-9.11(14.20)$ & 19.69 & 632 & 241 & 278 \\
\hline Employment & $1.99(2.35)$ & 19.46 & 955 & 385 & 386 \\
\hline \multicolumn{6}{|l|}{ Panel E: 2003} \\
\hline Turnover & $332.94(445.92)$ & 12.78 & 577 & 138 & 192 \\
\hline Exports & $-260.35(415.11)$ & 15.42 & 130 & 35 & 54 \\
\hline Investment & $-7.78(19.83)$ & 13.00 & 433 & 94 & 148 \\
\hline Employment & $-0.12(2.49)$ & 17.09 & 577 & 176 & 272 \\
\hline \multicolumn{6}{|l|}{ Panel F: 2004} \\
\hline Turnover & $367.21(295.79)$ & 19.59 & 528 & 164 & 295 \\
\hline Exports & $180.58(253.08)$ & 12.80 & 108 & 19 & 41 \\
\hline Investment & $-17.15(16.48)$ & 11.67 & 357 & 72 & 118 \\
\hline Employment & $1.71(2.54)$ & 14.06 & 528 & 126 & 208 \\
\hline \multicolumn{6}{|l|}{ Panel G: 2005} \\
\hline Turnover & $825.30 *(382.53)$ & 14.23 & 498 & 107 & 189 \\
\hline Exports & $402.82(228.55)$ & 16.12 & 109 & 24 & 45 \\
\hline Investment & $-10.67(10.59)$ & 13.90 & 330 & 76 & 109 \\
\hline Employment & $-0.31(2.14)$ & 22.87 & 498 & 146 & 321 \\
\hline
\end{tabular}

Notes: * indicates significance at the 5 percent level. Standard errors are shown in parentheses. Turnover, investment and exports are denoted in EUR 1000. The number of observations refer to the $\pm 25 \mathrm{MWh}$ region around the threshold c. The bandwidth is selected based on the procedure in The bandwidth is selected based on the procedure in Imbens and Kalyanaraman (2012). Source: Research Data Centres of the Statistical Offices Germany (2014): Official Firm Data for Germany (AFiD) - AFiD-Panel Industrial Units, AFiD-Module Use of Energy, and Cost Structure Survey, own calculations. 
number of firms to conduct a regression discontinuity analysis. On average, this group shows higher turnover and exports and is less energy intensive in comparison to the full population 14

In Table 6 we show the estimated effects of the tax reduction on the outcome variables turnover, exports, investment, and employment for each year in the period 1999-2005. We cannot estimate the effects on value added given too few observations from the sampled Cost Structure Survey. We apply local linear regressions and choose bandwidths optimally selected by applying Imbens and Kalyanamaran (2012) as in Section 5.3 . The results do not provide evidence for a significant and systematic effect of the electricity tax reduction on the outcome variables. Only one out of thirty-five treatment effects is statistically significant. As for the whole population, the results show a significant effect on exports in 2005.

The second subpopulation we investigate are firms that manufacture basic metals and fabricated metal products 15 The manufacturing of metals is a very energy-intensive manufacturing sector. This group should therefore be more sensitive with regard to changes in electricity prices. On average, firms of this group use higher amounts of electricity per unit of output, produce less output in terms of turnover and export less than the average firm of the full population. Table 7 shows the treatment effect for manufacture of basic metals and fabricated metal products. The local treatment effect of the electricity tax reduction on turnover is significantly positive in 2005. All other effects are statistically insignificant. Even for this more homogenous and energy intensive sector, we do not find evidence for a significant and systematic effect of the electricity tax reduction.

For both subsamples we note in addition that the point estimates of the sub sample analysis differ unsystematically from the point estimates resulting from the analysis on the whole sample. Hence we do observe any trend in the size of effects within the subpopulations, as may have been expected for the more energy-intensive manufacturing of metals. The standard errors of the sub sample analysis are larger compared to the results of the preceding analysis. This decrease in precision can be explained with the lower number of observations.

\section{Discussion}

While our results do not show any systematic, statistically significant effects of the reduced tax rate on the the economic performance of firms, we discuss in this section several factors that may have influenced our findings. Thereby we also draw attention to related and future research. First, we discuss the statistical power of our analysis. Then, we assess the likelihood and implications of a possible violation of SUTVA. Finally, we

\footnotetext{
${ }^{14}$ In Appendix E Table 12 and 13 , we show detailed descriptive statistics of the two sub populations under investigation.

${ }^{15}$ According to ISIC Rev. 3.1: manufacture of basic metals (27) and manufacture of fabricated metal products, except machinery and equipment (28)
} 
debate how our local results may relate to a wider set of firms.

Several factors influence the power of a statistical analysis, i.e., the correct rejection of the null hypothesis of no effects, when it is false. While some factors suggest that the power of our analysis is high, others suggest the opposite, with neither side clearly dominating.

First, we discuss the magnitude of the effect. If the size of effects is small, statistical power tends to be low. In our case the electricity tax strongly changes the price of electricity. During the period under investigation, it increases the pre-tax price of electricity by 15 to 27 percent on average as shown in Section 2 . This is a large change that suggests an effect of significant magnitude. Note in addition, that the change in electricity price is large in comparison to the Climate Change Levy in the United Kingdom, for which Martin, Muûls, and Wagner (2014) also did find no negative effects on economic outcomes. Using the same bandwidth of electricity use the CCL amounted only to 7 to 11 percent of the pre-tax price of electricity in 2001 (Eurostat, 2014, own calculations), when it was introduced at a level of GPB 4.35 per MWh. However, one should also note that electricity is only one of many inputs to production. So even if the price for a unit of electricity changes strongly the overall impact on firms may be limited. This suggests a small magnitude of the effect. Taking both sides of the above argument into account, there is no unequivocal expectation on the magnitude of the effects and hence the power of the analysis.

Second, our data is fairly heterogeneous. This leads to a risk of not rejecting the null hypothesis although the null hypothesis is false for at least some firms. To account for such a possibility we analyzed different subsectors in the previous section. We did not find any significant effects either.

Third, we draw our attention to sample size and measurement error. Low sample size and high measurement error would suggest low statistical power. Except for value added our data are based on censuses, and hence for almost all variables there is no uncertainty in how well our sample captures the population of firms. In addition, the number of observations is typically large. We also do not expect significant measurement error given that the data is collected through censuses and surveys that are mandatory by law. Both population data and low measurement error speak in favor of high statistical power.

So far, we have not discussed to what extent effects on the treated firms may induce additional effects on untreated firms. If such effects would occur the stable unit of treatment value assumption (SUTVA) would be violated. In the following paragraphs we discuss a likely violation of SUTVA, what its effect would be, and if we can find any evidence for such a violation.

The interaction of treated and untreated firms in common markets may violate SUTVA. Let us assume that there was a positive direct effect of the reduced tax rate on turnover for a treated firm, as marginal production costs have decreased compared to the level of the full tax rate, and lower production costs enable higher production levels. 
If this treated firm is in competition with another untreated firm in the same market, the treatment may have spill-over effects to the untreated firm. In particular, the treated firm may gain additional market share by lowering the product price to a level where the untreated firm, that has higher marginal costs, cannot or less well compete. In such a situation the positive spill-over effect would add to the positive direct effect of the tax reduction.

While we are not able to distinguish for a single year what part of the total effect consists of the direct effect of the reduced tax rate or the spill-over effects from being able to gain market share through altering prices, we can assess whether hypothesized effects are particularly strong for the year when the treatment was strongest. Going back to Table 3 in Section 5.3 we do not observe particularly strong effects for the year 2002 when the difference between the full and the reduced tax rate was highest, in particular when dividing total effects by the size of the tax reduction. Furthermore, effect signs are mostly negative, which is not in line with a positive spill-over effect due to reduced marginal costs. In addition estimates are statistically insignificant except for a negative coefficient for investments. Taken together, we do not observe strong evidence that SUTVA is violated due to spill-over effects.

Last but not least we debate how our local results may relate to a wider set of firms. Looking back at Table 2 and Figure 2 in Section 4.3 the analyzed firms fall within the lower quintile of energy use. While small, energy-intensive firms as well as larger, less energy-intensive firms are covered by our analysis, large energy-intensive firms are hardly covered. This raises the question whether our results would also apply to large, energy-intensive firms. What speaks in favor, is that we analyze a wide set of firms from different sectors and thereby capture the impact of the reduced tax rate on many different firms and that therefore larger firms are unlikely to differ systematically from smaller firms. What speaks against the application of our results to larger firms is the assertion that larger firms are indeed different from smaller firms and that therefore our results should be strictly regarded as local treatment effects. Taken together, no clear statement can be made in how far our results apply to larger firms. The best way forward may be to look out for similar experiments in tax rates or levies that do apply to larger firms.

Another related question is in how far our results are relevant for policy, given that we assessed the effects of a tax reduction for relatively small firms, while they may be more relevant for larger firms. It should be noted that the tax reduction was granted precisely for mitigating any negative impacts on firm's performance and particularly exports. Given that we do not find any positive effects of a reduced tax rate on firm's performance, or in other words any negative effects of higher electricity taxes, this puts doubts on the necessity of the tax reduction for domestic economic reasons. While we cannot rule out that large, energy-intensive firms may be affected differently than smaller firms by the electricity tax, we can say at least that the tax reduction is not well targeted for its purpose. Tax revenues are forgone by providing relief to firms that are not found 
to be vulnerable to higher electricity taxes.

\section{Conclusion}

This paper analyzes the causal impacts of the German electricity tax on the economic performance of firms in the manufacturing sector. The tax was implemented in 1999 and firms with electricity use above a certain threshold were eligible for a reduced electricity tax rate. We evaluate the effects of the reduced marginal electricity tax rate on five variables of economic performance, namely turnover, exports, investment, employment and value added with a regression discontinuity analysis. No robust positive or negative impact of the reduced marginal electricity tax rate is found. Hence our results indicate that firms forced to pay the full electricity tax rate did not suffer from deterioration in their economic performance.

Our findings suggest that the reduced electricity tax rate may not be needed for providing relief to firms in the manufacturing sector. Firms that had to pay the higher electricity tax did not perform worse than firms that only had to pay the reduced electricity tax rate. There are thus reasons to expect that firms that had to pay only the reduced electricity tax would adjust smoothly.

If there are doubts about the possibilities to adjust to higher electricity taxes for some firms with substantially higher electricity use than investigated, the reduced electricity tax rate could be removed stepwise by increasing the threshold for eligibility of the reduced tax rate over time, accompanied with a causal evaluation of its impacts. Removing the reduced tax rate would raise revenues for the government that could be used to decrease more distorting taxes, to consolidate budgets, or to finance new investments.

\section{Acknowledgements}

We thank Andreas Löschel, Kathrine von Graevenitz, Ralf Martin, Jonathan Goyette, Ulrich Wagner, Katrin Sommerfeld, Nico Pestel, Andreas Gerster, Stefan Lamp, and Stefan Vögele for suggestions and insightful comments. We grateful acknowledge the Research Data Centre (FDZ) of the Federal Statistical Office and the Statistical Offices of the German Länder for granting us access to the AFiD data and for the use of their research facilities, in particular Michael Rößner for his advice and technical support regarding the estimation of our empirical model. The paper has also benefited from discussions with participants of the ASSA Meeting 2015, the $6^{\text {th }}$ AWEEE 2014, the $37^{\text {th }}$ IAEE International Conference 2014, and the $19^{\text {th }}$ SMYE 2014. We also thank the participants of internal seminars and meetings at OECD and ZEW and colleagues at OECD and ZEW for informal discussions. Benjamin Johannes Lutz thanks the Helmholtz Association for the financial support through the Helmholtz Alliance ENERGY-TRANS. The views expressed in this paper are those of the authors and do not necessarily represent those of the OECD, ZEW or the FDZ. 


\section{References}

Arlinghaus, J. (forthcoming): "Competitiveness Impacts of Carbon Pricing: A review of empirical findings," OECD Environment Working Paper, OECD Publishing, Paris.

Bosquet, B. (2000): "Environmental tax reform: does it work? A survey of the empirical evidence," Ecological Economics, 34, 19-32.

Calonico, S., M. D. Cattaneo, and T. Rocio (2014a): "Robust Data-Driven Inference in the Regression-Discontinuity Design," Revision Requested by The Stata Journal. Available at http://www-personal.umich.edu/ cattaneo/papers/CalonicoCattaneo-Titiunik_2013_Stata.pdf.

(2014b): "Robust Nonparametric Confidence Intervals for RegressionDiscontinuity Designs," Revision Requested by Econometrica. Available at http://www-personal.umich.edu/ cattaneo/papers/RD-robust.pdf.

Eurostat (2014): "Electricity prices of industrial (nrg_pc_205_h) and domestic consumers (nrg_pc_204_h)," extracted on 4th of August, 2014.

Fowlie, M., S. P. Holland, And E. T. Mansur (2012): "What Do Emissions Markets Deliver and to Whom? Evidence from Southern California's NOx Trading Program," American Economic Review, 102(2), 965-93.

Hahn, J., J. Todd, and van der Klaauw (2001): "Identification and Estimation of Treatment Effects with a Regression-Discontinuity Design," Econometrica, 69(1), 201-209.

Imbens, G., and K. Kalyanaraman (2011): "Optimal bandwidth choice for the regression discontinuity estimator," The Review of Economic Studies, p. rdr043.

Imbens, G. W., And T. Lemieux (2008): "Regression Discontinuity Designs: A Guide to Practice," Journal of Econometrics, 142(2), 615-635.

LEE, D. S. (2008): "Randomized Experiments from Non-random Selection in U.S. House Elections," Journal of Econometrics, 142(2), 675-697.

Lee, D. S., And T. Lemieux (2010): "Regression Discontinuity Designs in Economics," Journal of Economic Literature, 48(2), 281-355.

Martin, R., L. B. De Preux, and U. J. Wagner (2014): "The impact of a carbon tax on manufacturing: Evidence from microdata," Journal of Public Economics, 117, $1-14$.

Martin, R., M. Mû̂ls, and U. J. Wagner (2013): "The Impact of the EU ETS on Regulated Firms: What is the Evidence After Eight Years?," Available at SSRN: http://papers.ssrn.com/sol3/papers.cfm?abstract_id=2344376. 
MCCRARY, J. (2008): "Manipulation of the running variable in the regression discontinuity design: A density test," Journal of Econometrics, 142(2), 698 - 714, The regression discontinuity design: Theory and applications.

Montgomery, W. D. (1972): "Markets in Licenses and Efficient Pollution Control Programs," Journal of Economic Theory, 5(3), 395-418.

Pearl, J. (2000): Causality: Models, Reasoning, and Inference. Cambridge University Press, New York.

Petrick, S., And U. Wagner (2014): "The Impact of Carbon Trading on Industry: Evidence from German Manufacturing Firms," Available at SSRN: http://papers.ssrn.com/sol3/papers.cfm?abstract_id=2389800.

Pigou, A. C. (1920): The Economic of Welfare. Macmillan and Company, London.

Porter, J. (2003): "Estimation in the Regression Discontinuity Model," Working Paper, University of Wisconsin. Available at http://www.ssc.wisc.edu/ jrporter/reg_discont_2003.pdf.

Research Data Centres of the Statistical Offices Germany (2014): "AFiDPanel Industrial Units, AFiD-Module Use of Energy, and Cost Structure Survey 19952010," Further information: http://www.forschungsdatenzentrum.de/en/index.asp.

Rubin, D. (1974): "Estimating causal effects of treatments in randomized and nonrandomized studies," Journal of Educational Psychology, 66, 688-701.

(1977): "Assignment to a treatment group on the basis of a covariate," Journal of Educational Statistics, 2, 1-26.

Stavins, R. N. (1998): "What Can We Learn from the Grand Policy Experiment? Lessons from $\mathrm{SO}_{2}$ Allowance Trading," Journal of Economic Perspectives, 12(3), 6988. 


\section{Appendix}

\section{A Additional information on electricity intensity}

In order to depict the relationship between electricity intensity and total electricity use, we show scatter plots of non-overlapping binned local means and second order global polynomial functions of the variable electricity intensity in Figures 9 and 10 . The local means are computed for $1 \mathrm{MWh}$ bandwidths in the area of $25-75 \mathrm{MWh}$, the $c \pm 25$ MWh neighborhood surrounding the prevailing threshold.

Figure 9: Outcomes in the pretreatment year 1995.

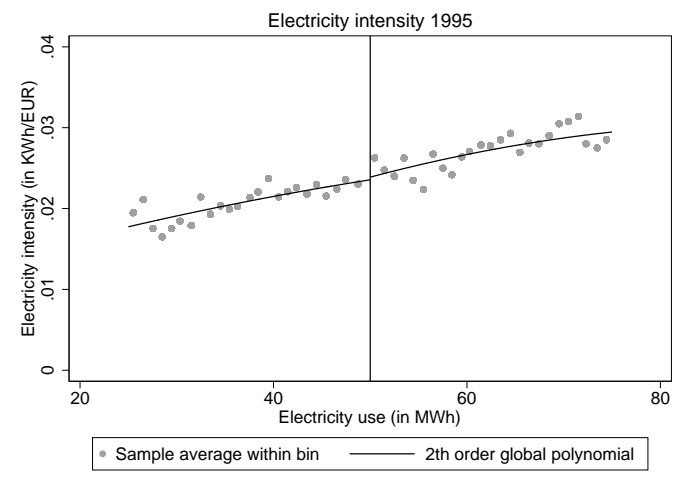

Notes: Source: Research Data Centres of the Statistical Offices Germany (2014): Official Firm Data for Germany (AFiD) - AFiD-Panel Industrial Units and AFiD-Module Use of Energy, own calculations.

Figure 10: Discontinuity effect of the reduction on the marginal tax rate.
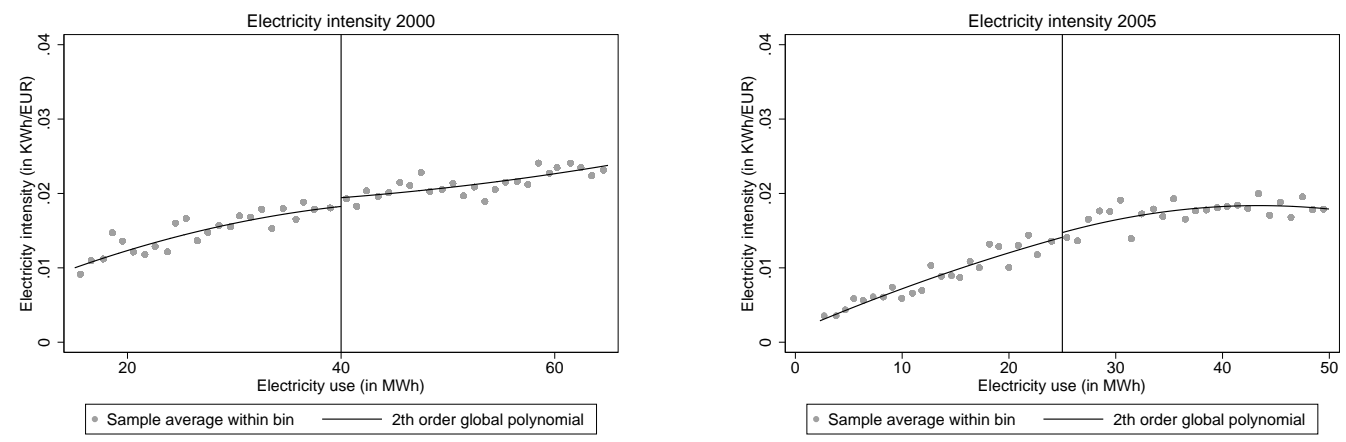

Notes: Assignment variable: electricity use. Outcome variable: electricity intensity. Source: Research Data Centres of the Statistical Offices Germany (2014): Official Firm Data for Germany (AFiD) - AFiD-Panel Industrial Units and AFiD-Module Use of Energy, own calculations. 


\section{B The effect of alternative kernel choices}

In this section, we provide evidence for the robustness of our findings with regard to the kernel choice. In particular, we show local average treatment effects using uniform (Table 8) and Epanechnikov kernel functions (Table 9) for the local linear regressions. The alternative kernel choice does not change qualitative results.

Table 8: Uniform kernel function.

\begin{tabular}{|c|c|c|c|c|c|}
\hline \multirow[t]{2}{*}{ Outcome variable } & \multirow[t]{2}{*}{ Estimator } & \multirow[t]{2}{*}{ Bandwidth } & \multicolumn{3}{|c|}{ Number of observations } \\
\hline & & & $\mathrm{c} \pm 25 \mathrm{MWh}$ & Control group & Treatment group \\
\hline \multicolumn{6}{|l|}{ Panel A: 1999} \\
\hline Turnover & $139.38(186.33)$ & 17.43 & 5,289 & 1,953 & 1,807 \\
\hline Exports & $-85.83(122.87)$ & 10.96 & 2,330 & 489 & 554 \\
\hline Investment & $-5.75(15.91)$ & 12.11 & 3,873 & 1,342 & 1,277 \\
\hline Employment & $-0.42(1.06)$ & 17.82 & 5,289 & 2,002 & 1,835 \\
\hline Value added & $-125.60(213.34)$ & 15.41 & 1,452 & 488 & 456 \\
\hline \multicolumn{6}{|l|}{ Panel B: 2000} \\
\hline Turnover & $-157.45(193.11)$ & 16.27 & 5,017 & 1,743 & 1,615 \\
\hline Exports & $-32.13(121.35)$ & 12.90 & 2,137 & 539 & 562 \\
\hline Investment & $-1.55(12.60)$ & 12.87 & 3,691 & 1,001 & 950 \\
\hline Employment & $-0.05(1.24)$ & 13.72 & 5,014 & 1,434 & 1,338 \\
\hline Value added & $-93.90(219.98)$ & 21.07 & 1,301 & 387 & 382 \\
\hline \multicolumn{6}{|l|}{ Panel C: 2001} \\
\hline Turnover & $443.39 *(286.44)$ & 12.75 & 4,862 & 1,242 & 1,347 \\
\hline Exports & $-145.09(133.01)$ & 12.29 & 2,041 & 478 & 540 \\
\hline Investment & $7.56(10.74)$ & 12.30 & 3,338 & 842 & 898 \\
\hline Employment & $0.50(1.03)$ & 20.10 & 4,859 & 1,829 & 2,077 \\
\hline Value added & $148.56(235.13)$ & 14.89 & 1,119 & 312 & 369 \\
\hline \multicolumn{6}{|l|}{ Panel D: 2002} \\
\hline Turnover & $-520.72 *(265.37)$ & 9.51 & 5,072 & 937 & 1,021 \\
\hline Exports & $-97.99(114.00)$ & 13.93 & 2,114 & 536 & 630 \\
\hline Investment & $-20.82(10.78)$ & 16.13 & 3,360 & 970 & 1,197 \\
\hline Employment & $0.46(1.26)$ & 14.73 & 5,063 & 1,390 & 1,584 \\
\hline Value added & $-297.42(303.96)$ & 16.82 & 985 & 310 & 356 \\
\hline \multicolumn{6}{|l|}{ Panel E: 2003} \\
\hline Turnover & $-205.82(227.5)$ & 12.74 & 3,052 & 730 & 964 \\
\hline Exports & $-237.33(215.91)$ & 9.52 & 1,290 & 230 & 290 \\
\hline Investment & $-3.69(9.22)$ & 12.89 & 2,175 & 502 & 708 \\
\hline Employment & $-0.83(1.41)$ & 13.89 & 3,052 & 780 & 1,066 \\
\hline Value added & $-142.88(206.11)$ & 11.32 & 851 & 190 & 239 \\
\hline \multicolumn{6}{|l|}{ Panel F: 2004} \\
\hline Turnover & $278.38(233.69)$ & 10.42 & 2,779 & 527 & 776 \\
\hline Exports & $-136.71(160.78)$ & 11.10 & 1,138 & 198 & 354 \\
\hline Investment & $-1.66(9.14)$ & 13.20 & 1,979 & 452 & 706 \\
\hline Employment & $0.50(1.13)$ & 13.19 & 2,778 & 621 & 994 \\
\hline Value added & $102.98(237.72)$ & 11.18 & 704 & 138 & 226 \\
\hline \multicolumn{6}{|l|}{ Panel G: 2005} \\
\hline Turnover & $-172.18(275.96)$ & 9.73 & 2,654 & 450 & 680 \\
\hline Exports & $306.72(181.43)$ & 12.28 & 1,068 & 211 & 314 \\
\hline Investment & $17.17^{*}(8.39)$ & 13.30 & 1,856 & 412 & 629 \\
\hline Employment & $0.52(1.41)$ & 9.29 & 2,654 & 431 & 649 \\
\hline Value added & $-46.01(215.49)$ & 17.48 & 621 & 157 & 303 \\
\hline
\end{tabular}

Notes: * indicates significance at the 5 percent level. Standard errors are shown in parentheses. Turnover, investment and exports are denoted in EUR 1000. The number of observations refer to the $\pm 25 \mathrm{MWh}$ region around the threshold c. The bandwidth is selected based on the procedure in Imbens and Kalyanaraman (2012). Source: Research Data Centres of the Statistical Offices Germany (2014): Official Firm Data for Germany (AFiD) - AFiD-Panel Industrial Units, AFiD-Module Use of Energy, and Cost Structure Survey own calculations. 
Table 9: Epanechnikov kernel function.

\begin{tabular}{|c|c|c|c|c|c|}
\hline \multirow[t]{2}{*}{ Outcome variable } & \multirow[t]{2}{*}{ Estimator } & \multirow[t]{2}{*}{ Bandwidth } & \multicolumn{3}{|c|}{ Number of observations } \\
\hline & & & $\mathrm{c} \pm 25 \mathrm{MWh}$ & Control group & Treatment group \\
\hline \multicolumn{6}{|l|}{ Panel A: 1999} \\
\hline Turnover & $99.96(174.23)$ & 22.00 & 5,289 & 2,463 & 2,192 \\
\hline Exports & $-15.30(112.03)$ & 14.41 & 2,330 & 680 & 707 \\
\hline Investment & $-8.84(11.45)$ & 20.79 & 3,873 & 1,682 & 1,557 \\
\hline Employment & $-0.45(1.01)$ & 21.63 & 5,289 & 2,431 & 2,156 \\
\hline Value added & $-73.72(202.47)$ & 19.42 & 1,452 & 598 & 556 \\
\hline \multicolumn{6}{|l|}{ Panel B: 2000} \\
\hline Turnover & $-162.95(182.63)$ & 20.43 & 5,017 & 2,121 & 2,076 \\
\hline Exports & $-29.86(110.36)$ & 16.80 & 2,137 & 706 & 752 \\
\hline Investment & $-3.48(11.44)$ & 17.35 & 3,691 & 1,372 & 1,280 \\
\hline Employment & $-0.06(1.17)$ & 17.58 & 5,014 & 1,867 & 1,731 \\
\hline Value added & $1.98(204.78)$ & 18.37 & 1,301 & 499 & 477 \\
\hline \multicolumn{6}{|l|}{ Panel C: 2001} \\
\hline Turnover & $436.22^{*}(218.88)$ & 15.37 & 4,862 & 1,473 & 1,651 \\
\hline Exports & $-160.35(124.85)$ & 16.02 & 2,041 & 591 & 742 \\
\hline Investment & $9.58(10.10)$ & 15.59 & 3,338 & 1,003 & 1,175 \\
\hline Employment & $0.64(0.97)$ & 24.41 & 4,859 & 2,300 & 2,485 \\
\hline Value added & $165.92(215.22)$ & 18.61 & 1,119 & 383 & 460 \\
\hline \multicolumn{6}{|l|}{ Panel D: 2002 } \\
\hline Turnover & $-394.9(239.91)$ & 13.20 & 5,072 & 1,259 & 1,412 \\
\hline Exports & $-70.82(111.38)$ & 16.56 & 2,114 & 612 & 757 \\
\hline Investment & $-19.48(10.283)$ & 19.33 & 3,360 & 1,264 & 1,419 \\
\hline Employment & $0.09(1.14)$ & 18.49 & 5,063 & 1,925 & 1,973 \\
\hline Value added & $-446.43(301.25)$ & 20.60 & 985 & 354 & 469 \\
\hline \multicolumn{6}{|l|}{ Panel E: 2003} \\
\hline Turnover & $-161.33(222.86)$ & 15.13 & 3,052 & 861 & 1,193 \\
\hline Exports & $-234.40(152.83)$ & 11.90 & 1,290 & 265 & 376 \\
\hline Investment & $-4.24(8.56)$ & 16.69 & 2,175 & 618 & 979 \\
\hline Employment & $-0.63(1.33)$ & 17.35 & 3,052 & 917 & 1,399 \\
\hline Value added & $-182.57(186.50)$ & 14.75 & 851 & 232 & 320 \\
\hline \multicolumn{6}{|l|}{ Panel F: 2004} \\
\hline Turnover & $235.80(219.85)$ & 13.03 & 2,779 & 620 & 978 \\
\hline Exports & $-65.13(156.85)$ & 13.36 & 1,138 & 222 & 431 \\
\hline Investment & $-3.53(8.91)$ & 16.09 & 1,979 & 527 & 882 \\
\hline Employment & $0.54(1.06)$ & 16.70 & 2,778 & 743 & 1,276 \\
\hline Value added & $90.30(229.36)$ & 14.59 & 704 & 164 & 296 \\
\hline \multicolumn{6}{|l|}{ Panel G: 2005} \\
\hline Turnover & $-125.48(270.40)$ & 11.33 & 2,654 & 502 & 781 \\
\hline Exports & $328.80 *(166.92)$ & 15.86 & 1,068 & 256 & 438 \\
\hline Investment & $14.96(7.97)$ & 16.06 & 1,856 & 479 & 798 \\
\hline Employment & $0.50(1.34)$ & 11.52 & 2,654 & 505 & 790 \\
\hline Value added & $-18.37(211.83)$ & 21.35 & 621 & 175 & 373 \\
\hline
\end{tabular}

Notes: * indicates significance at the 5 percent level. Standard errors are shown in parentheses. Turnover, investment and exports are denoted in EUR 1000. The number of observations refer to the $\pm 25 \mathrm{MWh}$ region around the threshold c. The bandwidth is selected based on the procedure in Imbens and Kalyanaraman (2012). Source: Research Data Centres of the Statistical Offices Germany (2014): Official Firm Data for Germany (AFiD) - AFiD-Panel Industrial Units, AFiD-Module Use of Energy, and Cost Structure Survey own calculations. 


\section{The effect of bandwidth choice}

In order to examine the sensitivity of results to different bandwidth choices, we estimate the local average treatment effect for 5, 10, 15, 20, and 25 MWh bandwidths. Table 10 shows the results for the treatment years 1999 - 2005. Figure 11 shows the local average treatment effects of the tax reduction on turnover in 2001 and investment in 2002 as a function of bandwidth choice.

Table 10: LATE estimates for 5, 10, 15, 20, and 25 MWh bandwidths.

\begin{tabular}{|c|c|c|c|c|c|}
\hline \multirow[t]{2}{*}{ Outcome variable } & \multicolumn{5}{|c|}{ Bandwidth (in MWh) } \\
\hline & 5 & 10 & 15 & 20 & 25 \\
\hline \multicolumn{6}{|l|}{ Panel A: 1999} \\
\hline Turnover & $117.48(317.93)$ & $239.87(244.65)$ & $110.45(207.22)$ & $119.26(185.22)$ & $96.74(167.17)$ \\
\hline Exports & $-42.64(205.45)$ & $-70.05(137.65)$ & $-18.05(112.55)$ & $26.74(97.59)$ & $24.70(86.83)$ \\
\hline Investment & $-25.07(24.10)$ & $-15.78(16.53)$ & $-10.43(13.66)$ & $-9.00(12.02)$ & $-10.84(10.73)$ \\
\hline Employment & $0.96(1.74)$ & $-0.49(1.37)$ & $-0.68(1.18)$ & $-0.50(1.06)$ & $-0.31(0.96)$ \\
\hline Value added & $-393.99(366.91)$ & $-127.31(272.50)$ & $-101.02(231.67)$ & $-82.34(205.11)$ & $-63.02(183.16)$ \\
\hline \multicolumn{6}{|l|}{ Panel B: 2000} \\
\hline Turnover & $-450.60(407.13)$ & $-261.96(276.13)$ & $-189.04(221.20)$ & $-168.92(191.06)$ & $-154.24(171.41)$ \\
\hline Exports & $-278.31(219.16)$ & $-215.61(151.92)$ & $-95.03(122.01)$ & $-17.12(104.62)$ & $-0.34(92.90)$ \\
\hline Investment & $26.53(27.68)$ & $5.31(17.51)$ & $-0.36(13.47)$ & $-1.07(11.24)$ & $1.27(9.87)$ \\
\hline Employment & $-1.68(2.71)$ & $-1.59(1.75)$ & $-0.65(1.35)$ & $-0.07(1.15)$ & $0.10(1.02)$ \\
\hline Value added & $-649.01(370.99)$ & $-377.52(267.74)$ & $-161.32(225.62)$ & $-20.71(201.03)$ & $44.75(183.63)$ \\
\hline \multicolumn{6}{|l|}{ Panel C: 2001} \\
\hline Turnover & $862.92 *(410.84)$ & $585.95 *(282.79)$ & $479.47 *(229.00)$ & $401.60 *(198.85)$ & $365.53^{*}(177.81)$ \\
\hline Exports & $-447.05 *(221.06)$ & $-196.72(159.24)$ & $-163.59(132.39)$ & $-203.16(115.62)$ & $-198.11(103.18)$ \\
\hline Investment & $-8.46(16.92)$ & $5.71(12.526)$ & $8.26(10.46)$ & $8.55(9.28)$ & $8.62(8.41)$ \\
\hline Employment & $0.31(2.10)$ & $0.25(1.51)$ & $0.51(1.25)$ & $0.41(1.10)$ & $0.59(0.98)$ \\
\hline Value added & $512.99(361.72)$ & $410.13(261.56)$ & $251.77(231.15)$ & $187.23(209.65)$ & $140.40(192.57)$ \\
\hline \multicolumn{6}{|l|}{ Panel D: 2002} \\
\hline Turnover & $-582.48(369.92)$ & $-458.00(278.24)$ & $-347.30(231.72)$ & $-109.13(199.41)$ & $-20.128(182.54)$ \\
\hline Exports & $144.04(247.47)$ & $6.66(152.31)$ & $-46.47(121.53)$ & $-42.79(102.78)$ & $-28.10(93.50)$ \\
\hline Investment & $-36.21(19.31)$ & $-31.75^{*}(14.97)$ & $-26.53^{*}(12.33)$ & $-21.04 *(10.47)$ & $-18.90^{*}(9.57)$ \\
\hline Employment & $1.55(2.18)$ & $-0.49(1.62)$ & $-0.45(1.34)$ & $0.126(1.14)$ & $0.20(1.03)$ \\
\hline Value added & $-972.51 *(495.41)$ & $-874.32 *(444.76)$ & $-746.64 *(367.99)$ & $-528.14(313.00)$ & $-481.94(285.39)$ \\
\hline \multicolumn{6}{|l|}{ Panel E: 2003} \\
\hline Turnover & $33.23(401.90)$ & $23.86(286.46)$ & $-125.67(231.83)$ & $-186.62(201.78)$ & $-215.76(185.30)$ \\
\hline Exports & $-436.06(266.66)$ & $-265.37(182.88)$ & $-181.41(139.74)$ & $-68.66(117.95)$ & $-32.77(108.96)$ \\
\hline Investment & $12.59(14.15)$ & $-0.67(11.10)$ & $-2.31(9.28)$ & $-4.73(8.15)$ & $-4.02(7.58)$ \\
\hline Employment & $1.92(2.66)$ & $0.80(1.87)$ & $-0.26(1.50)$ & $-0.53(1.30)$ & $-0.55(1.19)$ \\
\hline Value added & $-80.35(307.41)$ & $-173.59(226.77)$ & $-175.64(189.31)$ & $-202.80(166.43)$ & $-185.66(53.37)$ \\
\hline \multicolumn{6}{|l|}{ Panel F: 2004} \\
\hline Turnover & $711.13^{*}(322.74)$ & $332.62(250.54)$ & $236.29(210.94)$ & $125.90(186.67)$ & $63.04(172.21)$ \\
\hline Exports & $15.37(269.11)$ & $-87.37(193.97)$ & $-39.11(154.74)$ & $39.89(132.73)$ & $98.11(121.01)$ \\
\hline Investment & $4.19(17.16)$ & $-4.57(12.48)$ & $-2.48(9.83)$ & $-5.42(8.40)$ & $-6.07(7.69)$ \\
\hline Employment & $5.03 *(1.77)$ & $2.72 *(1.36)$ & $1.15(1.13)$ & $0.64(1.01)$ & $0.63(0.94)$ \\
\hline Value added & $137.17(392.29)$ & $135.98(292.62)$ & $93.51(237.09)$ & $52.87(204.60)$ & $56.77(186.15)$ \\
\hline \multicolumn{6}{|l|}{ Panel G: 2005} \\
\hline Turnover & $137.01(378.05)$ & $-79.77(290.82)$ & $-149.71(244.83)$ & $-216.97(216.96)$ & $-309.6(198.33)$ \\
\hline Exports & $448.81(267.83)$ & $362.2(203.21)$ & $323.35(174.51)$ & $345.12^{*}(154.47)$ & $327.60 *(140.93)$ \\
\hline Investment & $17.57(12.47)$ & $10.28(9.83)$ & $14.21(8.41)$ & $13.70(7.48)$ & $10.88(6.86)$ \\
\hline Employment & $3.02(1.95)$ & $1.10(1.45)$ & $0.31(1.23)$ & $0.39(1.10)$ & $0.52(1.02)$ \\
\hline Value added & $-569.45(552.83)$ & $-189.10(337.20)$ & $-56.01(262.19)$ & $-35.54(228.33)$ & $-42.74(208.33)$ \\
\hline
\end{tabular}

Notes: * indicates significance at the 5 percent level. Standard errors are shown in parentheses. Turnover, investment and exports are denoted in EUR 1000. The number of observations refer to the $\pm 25 \mathrm{MWh}$ region around the threshold c. Source: Research Data Centres of the Statistical Offices Germany (2014): Official Firm Data for Germany (AFiD) - AFiD-Panel Industrial Units, AFiD-Module Use of Energy, and Cost Structure Survey own calculations. 
Figure 11: The effect of bandwidth choice on point estimates and confidence intervals.
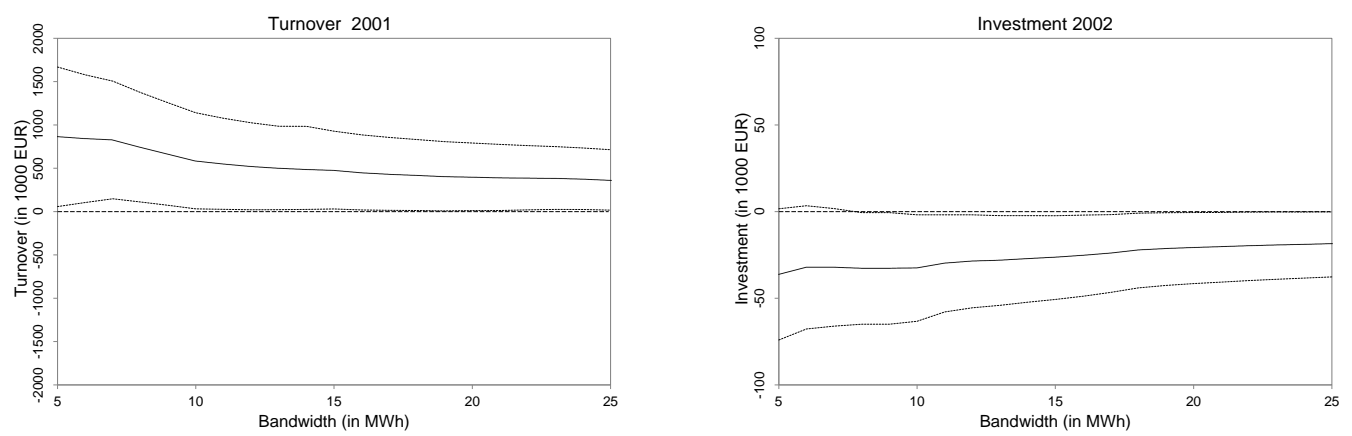

Notes: The solid black line in each panel denotes point estimates and the dashed lines are corresponding 95 percent confidence intervals. Source: Research Data Centres of the Statistical Offices Germany (2014): Official Firm Data for Germany (AFiD) - AFiD-Panel Industrial Units, AFiD-Module Use of Energy, and Cost Structure Survey, own calculations. 


\section{Dynamic local average treatment effects}

Table 11 shows lagged local average treatment effects. The estimators indicate that the results of our analysis are robust with respect to potential adjustment processes that might lead to delayed effects of the tax reduction.

Table 11: Dynamic local average treatment effects.

\begin{tabular}{|c|c|c|c|c|c|}
\hline \multirow{2}{*}{ Outcome variable } & \multirow[t]{2}{*}{ Estimator } & \multirow{2}{*}{ Bandwidth } & \multicolumn{3}{|c|}{ Number of observations } \\
\hline & & & $\mathrm{c} \pm 25 \mathrm{MWh}$ & Control group & Treatment group \\
\hline \multicolumn{6}{|c|}{ Panel A: Effect of the discontinuity in 1999 on outcome in 2000} \\
\hline Turnover & $7.47(217.70)$ & 21.07 & 4,672 & 2,053 & 1,893 \\
\hline Exports & $-73.96(114.51)$ & 22.39 & 2,107 & 919 & 997 \\
\hline Investment & $8.75(12.92)$ & 21.41 & 3,575 & 1,595 & 1,477 \\
\hline Employment & $-1.35(1.12)$ & 21.09 & 4,665 & 2,052 & 1,896 \\
\hline Value added & $-133.27(208.29)$ & 19.05 & 1,375 & 559 & 527 \\
\hline \multicolumn{6}{|c|}{ Panel B: Effect of the discontinuity in 2000 on outcome in 2001} \\
\hline Turnover & $68.76(189.15)$ & 30.97 & 4,403 & 2,179 & 2,224 \\
\hline Exports & $-156.23(146.81)$ & 16.98 & 1,900 & 633 & 663 \\
\hline Investment & $7.24(12.40)$ & 19.13 & 3,215 & 1,270 & 1,245 \\
\hline Employment & $0.47(1.11)$ & 28.057 & 4,403 & 2,185 & 2,218 \\
\hline Value added & $-137.59(250.69)$ & 14.55 & 1,151 & 333 & 344 \\
\hline \multicolumn{6}{|c|}{ Panel C: Effect of the discontinuity in 2001 on outcome in 2002 } \\
\hline Turnover & $524.44 *(259.06)$ & 16.93 & 4,148 & 1,312 & 1,578 \\
\hline Exports & $-66.78(137.73)$ & 19.96 & 1,749 & 580 & 811 \\
\hline Investment & $2.52(10.44)$ & 21.30 & 2,891 & 1,223 & 1,369 \\
\hline Employment & $0.30(1.18)$ & 22.13 & 4,148 & 1,794 & 1,997 \\
\hline Value added & $420.40(308.58)$ & 15.02 & 1,020 & 284 & 337 \\
\hline \multicolumn{6}{|c|}{ Panel D: Effect of the discontinuity in 2002 on outcome in 2003} \\
\hline Turnover & $-240.08(235.97)$ & 17.929 & 4,255 & 1,574 & 1,631 \\
\hline Exports & $29.96(143.29)$ & 18.77 & 1,862 & 672 & 774 \\
\hline Investment & $-3.41(9.29)$ & 19.86 & 2,983 & 1,145 & 1,324 \\
\hline Employment & $-0.28(1.33)$ & 19.53 & 4,255 & 1,649 & 1,830 \\
\hline Value added & $-159.47(337.57)$ & 19.67 & 1,149 & 452 & 497 \\
\hline \multicolumn{6}{|c|}{ Panel E: Effect of the discontinuity in 2003 on outcome in 2004} \\
\hline Turnover & $-235.37(224.35)$ & 16.97 & 2,842 & 853 & 1,271 \\
\hline Exports & $-259.18(217.54)$ & 10.56 & 1,195 & 234 & 315 \\
\hline Investment & $3.55(10.53)$ & 19.23 & 1,986 & 518 & 759 \\
\hline Employment & $-2.26(1.34)$ & 18.80 & 2,842 & 891 & 1,421 \\
\hline Value added & $-320.15(241.86)$ & 15.02 & 780 & 213 & 304 \\
\hline \multicolumn{6}{|c|}{ Panel F: Effect of the discontinuity in 2004 on outcome in 2005} \\
\hline Turnover & $440.04(279.36)$ & 12.60 & 2,572 & 564 & 864 \\
\hline Exports & $164.28(173.88)$ & 20.92 & 1,067 & 287 & 643 \\
\hline Investment & $15.18(12.22)$ & 13.52 & 1,749 & 410 & 621 \\
\hline Employment & $2.15(1.19)$ & 16.25 & 2,571 & 682 & 1,144 \\
\hline Value added & $179.16(311.78)$ & 11.08 & 645 & 125 & 198 \\
\hline \multicolumn{6}{|c|}{ Panel G: Effect of the discontinuity in 2005 on outcome in 2006} \\
\hline Turnover & $-274.6(279.77)$ & 14.07 & 2,393 & 546 & 868 \\
\hline Exports & $383.38(208.65)$ & 14.79 & 993 & 220 & 358 \\
\hline Investment & $9.41(12.10)$ & 14.33 & 1,729 & 396 & 638 \\
\hline Employment & $1.12(1.47)$ & 13.74 & 2,392 & 527 & 853 \\
\hline Value added & $-9.16(267.04)$ & 17.31 & 577 & 149 & 279 \\
\hline
\end{tabular}

Notes: * indicates significance at the 5 percent level. Standard errors are shown in parentheses. Turnover, investment and exports are denoted in EUR 1000. The number of observations refer to the $\pm 25 \mathrm{MWh}$ region around the threshold c. The bandwidth is selected based on the procedure in Imbens and Kalyanaraman (2012). Source: Research Data Centres of the Statistical Offices Germany (2014): Official Firm Data for Germany (AFiD) - AFiD-Panel Industrial Units, AFiD-Module Use of Energy, and Cost Structure Survey own calculations. 


\section{E Subsample analysis: descriptive statistics}

The subpopulation manufacture of machinery, electronic devices, and vehicles covers the industries 29 - 35 according to the ISIC Rev. 3.1 classification. In Table 12 we present the descriptive statistics of the assignment variable electricity use, electricity intensity, and the outcome variables considered in Section 5.6. Firms that manufacture machinery, electronic devices, and vehicles show on average higher turnovers and exports and are less electricity intensive in comparison to the full population. In terms of turnover and number of employees, the subpopulation is less heterogenous.

The subpopulation manufacture of basic metal and fabricated metal products comprises the industries 27 and 28 according to the ISIC Rev. 3.1 classification. The descriptive statistics in Table 13 show, that firms of this subspopulation produce less output in terms of turnover and export less than the average firm of the full population. Furthermore, when comparing average electricity intensities, we see that this industry is on average more energy intensive than the full population. With regard to turnover, number of employees, and electricity intensity, the subpopulation is less heterogenous.

Table 12: Descriptive statistics: manufacture of machinery, electronic devices, and vehicles.

\begin{tabular}{lcccccc}
\hline \hline & Mean & St. dev. & P10 & P 50 & P90 & N \\
\hline Panel A: 1995 & & & & & & \\
Electricity use (in MWh) & 972.99 & $2,716.51$ & 32.8 & 206.78 & 2188.13 & 10,758 \\
Turnover (in 1000 EUR) & $14,400.29$ & $24,750.78$ & $1,561.58$ & $5,644.63$ & $35,646.88$ & 10,769 \\
Exports (in 1000 EUR) & $2,622.11$ & $4,407.23$ & 0 & 606.87 & $12,316.20$ & 10,769 \\
Investment (in 1000 EUR) & 538.261 & $1,378.32$ & 0 & 120.45 & $1,326.61$ & 9,429 \\
Employment & 126.72 & 184.55 & 25.08 & 58.75 & 296.42 & 10,769 \\
Electricity intensity (in EUR per KWh) & 0.0615 & 0.0764 & 0.0087 & 0.0379 & 0.1385 & 10,758 \\
Panel B: 2000 & & & & & \\
Electricity use (in MWh) & $1,028.71$ & $2,978.79$ & 33.30 & 216.10 & $2,283.79$ & 11,319 \\
Turnover (in 1000 EUR) & $16,973.42$ & $29,564.06$ & $1,745.99$ & $6,376.33$ & $42,803.77$ & 11,324 \\
Exports (in 1000 EUR) & $6,104.53$ & $14,432.49$ & 0 & 877.08 & $16,644.36$ & 11,324 \\
Investment (in 1000 EUR) & 591.60 & $1,381.61$ & 0.21 & 137.20 & $1,483.91$ & 10,914 \\
Employment & 117.48 & 161.77 & 24.83 & 56.21 & 277.58 & 11,324 \\
Electricity intensity (in EUR per KWh) & 0.0573 & 0.0713 & 0.0077 & 0.0345 & 0.1290 & 11,319 \\
Panel C: 2005 & & & & & & \\
Electricity use (in MWh) & $1,189.87$ & $3,438.61$ & 45.44 & 262.49 & $2,603.56$ & 11,334 \\
Turnover (in 1000 EUR) & $18,332.25$ & $32,909.89$ & $1,671.67$ & $6,660.25$ & $45,592.08$ & 11,750 \\
Exports (in 1000 EUR) & $7,581.08$ & $17,913.27$ & 0 & $1,209.86$ & $20,499.69$ & 11,750 \\
Investment (in 1000 EUR) & 465.87 & 1169.16 & 0 & 94.88 & $1,143.12$ & 11,287 \\
Employment & 112.81 & 155.22 & 24.67 & 55.00 & 263.42 & 11,750 \\
Electricity intensity (in EUR per KWh) & 0.0653 & 0.0847 & 0.0104 & 0.0383 & 0.1488 & 11,259 \\
\hline \hline
\end{tabular}

Notes: Turnover, investment and exports are denoted in EUR 1000. Electricity use relates to the taxable electricity use in MWh (not including self-generated electricity). Electricity intensity is denoted by electricity use devided by turnover. Source: Research Data Centres of the Statistical Offices Germany (2014): Official Firm Data for Germany (AFiD) - AFiD-Panel Industrial Units, AFiD-Module Use of Energy, and Cost Structure Survey, own calculations. 
Table 13: Descriptive statistics: manufacture of basic metal and fabricated metal products.

\begin{tabular}{lcccccc}
\hline \hline & Mean & St. dev. & P10 & P 50 & P90 & N \\
\hline Panel A: 1995 & & & & & & \\
Electricity use (in MWh) & $1,541.63$ & $4,020.85$ & 35.05 & 317.32 & $3,512.14$ & 6,477 \\
Turnover (in 1000 EUR) & $11,596.03$ & $20,565.58$ & $1,640.40$ & $4,873.48$ & $26,272.04$ & 6,482 \\
Exports (in 1000 EUR) & $2,122.57$ & $6,644.29$ & 0 & 68.06 & $5,098.35$ & 6,482 \\
Investment (in 1000 EUR) & 485.21 & $1,131.52$ & 0 & 121.79 & $1,191.25$ & 5,810 \\
Employment & 99.90 & 143.96 & 24.58 & 51.92 & 215 & 6,482 \\
Electricity intensity (in EUR per KWh) & 0.1165 & 0.1417 & 0.0103 & 0.0687 & 0.2857 & 6,477 \\
Panel B: 2000 & & & & & \\
Electricity use (in MWh) & $1,686.35$ & $4,518.33$ & 36.00 & 347.90 & 3844.52 & 6,986 \\
Turnover (in 1000 EUR) & $12,415.21$ & $22,695.61$ & $1,730.20$ & $5,018.85$ & $28,806.22$ & 6,994 \\
Exports (in 1000 EUR) & $2,843.71$ & $9,110.51$ & 0 & 98.87 & $6,826.69$ & 6,994 \\
Investment (in 1000 EUR) & 559.73 & $1,343.42$ & 0 & 125.13 & $1,341.16$ & 6,752 \\
Employment & 91.65 & 127.76 & 24.08 & 48 & 197.75 & 6,994 \\
Electricity intensity (in EUR per KWh) & 0.1167 & 0.1397 & 0.0105 & 0.0709 & 0.2794 & 6,986 \\
Panel C: 2005 & & & & & & \\
Electricity use (in MWh) & $2,090.48$ & $5,228.09$ & 62.16 & 480 & $4,826.61$ & 6,783 \\
Turnover (in 1000 EUR) & $13,319.77$ & $24,694.88$ & $1,709.18$ & $5,102.57$ & $31,850.46$ & 6,963 \\
Exports (in 1000 EUR) & $3,680.77$ & $10,802.40$ & 0 & 190.61 & $9,462.13$ & 6,963 \\
Investment (in 1000 EUR) & 428.52 & $1,060.49$ & 0 & 83.61 & $1,078.46$ & 6,668 \\
Employment & 88.19 & 121.65 & 24 & 47.17 & 189.67 & 6,963 \\
Electricity intensity (in EUR per KWh) & 0.1428 & 0.1614 & 0.0180 & 0.0922 & 0.3239 & 6,737 \\
\hline \hline
\end{tabular}

Notes: Turnover, investment and exports are denoted in EUR 1000. Electricity use relates to the taxable electricity use in MWh (not including self-generated electricity). Electricity intensity is denoted by electricity use devided by turnover. Source: Research Data Centres of the Statistical Offices Germany (2014): Official Firm Data for Germany (AFiD) - AFiD-Panel Industrial Units, AFiD-Module Use of Energy, and Cost Structure Survey, own calculations. 